Alexandre Vital Leão

\title{
Remuneração de Executivos no Brasil: Relação Entre Remuneração e Performance no Novo Mercado
}

\section{Dissertação de Mestrado}

Dissertação apresentada como requisito parcial para obtenção de grau de Mestre pelo Programa de Pós-Graduação em Macroeconomia e Finanças do Departamento de Economia do Centro de Ciências Sociais da PUC-Rio.

Orientador: Prof. Ruy Monteiro Ribeiro 
Alexandre Vital Leão

\section{Remuneração de Executivos no Brasil: Relação Entre Remuneração e Performance no Novo Mercado}

Dissertação apresentada como requisito parcial para obtenção de grau de Mestre pelo Programa de Pós-Graduação em Macroeconomia e Finanças do Departamento de Economia do Centro de Ciências Sociais da PUC-Rio.

Prof. Ruy Monteiro Ribeiro

Orientador

Departamento de Economia - PUC-Rio

Prof. Walter Novaes Filho

Departamento de Economia - PUC-Rio

Prof. Ricardo Pereira Câmara Leal COPPEAD UFRJ

Prof. Augusto Cesar Pinheiro da Silva Vice-Decano Setorial de Pós-Graduação do Centro de Ciências Sociais - PUC-Rio 
Todos os direitos reservados. É proibida a reprodução total ou parcial do trabalho sem autorização da universidade, do autor e do orientador.

\section{Alexandre Vital Leão}

Graduado em Economia pela PUC-Rio em 2010. Cursou o Mestrado Profissional em Macroeconomia e Finanças, com ênfase em Finanças, pelo Departamento de Economia da PUC-Rio

Ficha Catalográfica

\section{Leão, Alexandre Vital}

Remuneração de Executivos no Brasil: Relação Entre Remuneração e Performance no Novo Mercado / Alexandre Vital Leão; orientador: Ruy Monteiro Ribeiro $-2017$

66 f.: il. color.; $30 \mathrm{~cm}$

Dissertação (mestrado) - Pontifícia Universidade Católica do Rio de Janeiro, Departamento de Economia, 2017.

Inclui bibliografia

1. Economia - Teses. 2. Remuneração de executivos. 3. Governança Corporativa. 4. Finanças Corporativas. 5. Problema do Agente-Principal. I. Ribeiro, Ruy Monteiro. II. Pontifícia Universidade Católica do Rio de Janeiro. Departamento de Economia. III. Título.

CDD: 330 


\section{Agradecimentos}

À minha família por todo apoio ao longo de toda minha vida. O apoio deles e o incentivo aos estudos foram imprescindíveis para que eu chegasse até aqui.

Ao meu orientador, Ruy Monteiro Ribeiro, por todo o apoio, orientação e conselhos, fundamentais para a conclusão deste trabalho, e por todo conhecimento transmitido ao longo do curso.

Aos membros da banca, Walter Novaes Filho e Ricardo Pereira Câmara Leal pelos comentários construtivos e pela colaboração na conclusão deste trabalho.

Às amizades que construí ao longo do curso, em especial Vinicius Bandeira, Thiago Pacheco, Daniel Belém, Felipe Rodrigo de Oliveira, Roberto Bandarra e Rodrigo Fonseca. 


\section{Resumo}

Leão, Alexandre Vital; Ribeiro, Ruy Monteiro. Remuneração de Executivos no Brasil: Relação Entre Remuneração e Performance no Novo Mercado. Rio de Janeiro, 2017. 66p. Dissertação de Mestrado Departamento de Economia, Pontifícia Universidade Católica do Rio de Janeiro.

O objetivo desse estudo é identificar as práticas de remuneração adotadas para os executivos no Brasil e medir a relação entre a performance das companhias e a remuneração desses executivos. Ao analisar a relação entre remuneração dos executivos e a performance das companhias, deveríamos observar uma relação positiva e estatisticamente (e economicamente) significante entre as duas variáveis, caso a elaboração dos contratos de remuneração dos executivos endereçassem os problemas mencionados na teoria do AgentePrincipal. Foram utilizadas diversas regressões para medir a sensibilidade entre a remuneração dos executivos e a performance das companhias. Podemos observar pelos resultados que, em algumas das regressões encontramos uma relação estatisticamente significante entre a remuneração dos executivos e a performance da companhia a um nível de significância de 5\%, no entanto, com um significado econômico muito baixo, o que parece inconsistente com o problema do AgentePrincipal.

\section{Palavras Chave}

Remuneração de Executivos; Governança Corporativa; Finanças Corporativas; Problema do Agente-Principal 


\section{Abstract}

Leão, Alexandre Vital; Ribeiro, Ruy Monteiro (Advisor). Executive Compensation in Brazil: The Relationship Between Compensation and Performance in the Novo Mercado. Rio de Janeiro, 2017. 66p. Dissertação de Mestrado - Departamento de Economia, Pontifícia Universidade Católica do Rio de Janeiro.

This paper seeks to identify and describe the executive compensation practices in Brazil, and measure the relationship between company performance and executive compensation in Brazil. When analyzing the relationship between executive compensation and company performance, we should observe a positive and statistically (and economically) significant relation between the two variables, in case the compensation contracts addressed the problems involved in the Principal-Agent theory. Several regressions were used to measure the sensibility between executive compensation and company performance. In some of the regressions we found a statistically significant relation between executive compensation and company performance at a 5\% significance level, but not economically significant, which seems to be inconsistent with the Principal-Agent theory.

\section{Keywords}

Executive Compensation; Corporate Governance; Corporate Finance; Principal-Agent Theory 


\section{Sumário}

1 Introdução $\quad 9$

2 Revisão de Literatura 11

3 Fundamentos Teóricos 17

$\begin{array}{ll}3.1 . \text { Histórico } & 17\end{array}$

3.1.1. Teoria do Agente-Principal 18

3.1.2. Relação Risco-Retorno 19

4 Base de Dados/Metodologia 21

4.1. Dados de Remuneração dos Executivos 21

4.2. Dados de Performance das Companhias 23

5 Os Componentes da Remuneração dos Executivos 25

6 Variação da Remuneração Entre as Empresas 30

7 Relação Entre Remuneração e Performance 32

7.1. Relação entre remuneração dos executivos e a variação no patrimônio dos acionistas 33

7.2. Controlando as Regressões Pelo Tamanho das Companhias 36

7.2.1. Relação entre a remuneração dos executivos e a variação no patrimônio dos acionistas, ponderando pelo Book Value das companhias

7.2.2. Relação entre a remuneração dos executivos e a variação no patrimônio dos acionistas, ponderando pela volatilidade das companhias

7.3. Relação entre a remuneração dos executivos e a performance contábil das companhias 
7.3.1. Receita Líquida

7.3.2. EBITDA (Earnings Before Interest, Taxes, Depreciation and Amortization) 42

7.3.3. Lucro Líquido 44

8 Conclusões 46

Referências bibliográficas 49

Anexo 1 50

Anexo 2 


\section{Introdução}

Dentre os tópicos que envolvem os diversos aspectos de governança corporativa, a remuneração de executivos é um dos que recebe maior atenção. Períodos de crises financeiras tendem a aumentar a repercussão desse tema nos diversos meios de comunicação no mundo todo: isso ocorreu em 2001 com os escândalos da Enron e da WorldCom e, mais recentemente, com a crise do Subprime em 2007 e 2008, onde apesar do prejuízo causado aos acionistas, diversos CEO's receberam bônus milionários.

Sempre houve muito debate sobre a remuneração de executivos, principalmente nos EUA, mas os estudos acadêmicos sobre o assunto começaram a surgir a partir da década de 1980, também principalmente nos EUA, em paralelo com o surgimento da Teoria dos Contratos e o problema do Agente-Principal. Para que haja um alinhamento de interesses entre o executivo e os acionistas, o primeiro deve ser remunerado de acordo com os retornos proporcionados ao segundo, ou seja: a remuneração do executivo deveria estar intrinsecamente relacionada à variação do patrimônio dos acionistas, de forma que deveríamos encontrar uma relação positiva e estatisticamente significante entre a remuneração dos executivos e a performance das companhias.

A literatura acadêmica no Brasil ainda é muito incipiente nesse tema, quando comparado aos estudos voltados ao mercado norte-americano, de forma que existem poucos estudos sobre a relação entre remuneração de executivos e a performance das companhias no Brasil. Um dos motivos para isso é o fato de que a divulgação da remuneração da diretoria estatutária é uma exigência recente da CVM, o que faz com que a base de dados de remuneração de executivos ainda seja muito pequena no país.

O objetivo desse estudo é identificar as práticas de remuneração adotadas para os executivos no Brasil e medir a relação entre a performance das companhias e a remuneração desses executivos. Foram utilizadas diversas 
regressões para medir a sensibilidade entre a remuneração dos executivos e a performance das companhias. Podemos observar pelos resultados que, em algumas das regressões encontramos uma relação estatisticamente significante entre a remuneração dos executivos e a performance da companhia a um nível de significância de 5\%, no entanto, com um significado econômico muito baixo, o que parece inconsistente com o problema do Agente-Principal.

A seção 2 traz uma revisão da literatura sobre a relação entre a remuneração dos executivos e a performance das companhias, citando alguns artigos nacionais e internacionais; a seção 3 explica os fundamentos teóricos que serviram de base para o estudo, mostrando porque deveríamos encontrar uma relação positiva e estatisticamente significante entre remuneração e performance de acordo com a Teoria do Agente-Principal e o princípio básico de Finanças da relação riscoretorno; a seção 4 explica a base de dados utilizada, informando de onde os dados de remuneração e performance foram extraídos; a seção 5 traz em maiores detalhes os diversos componentes de remuneração presentes na remuneração dos executivos; a seção 6 comenta as diferentes práticas de remuneração entre as empresas, por tamanho das companhias (large caps e small caps) e por setor de atuação; a seção 7 explica todas as regressões realizadas para testar a relação entre remuneração e performance; e a seção 8 traz a conclusão dos estudos. 


\section{Revisão de Literatura}

Diversos estudos internacionais vêm tentando investigar a relação entre remuneração e performance nas empresas de capital aberto. Os estudos acadêmicos sobre o assunto começaram a surgir a partir da década de 1980, principalmente nos EUA, em paralelo com o surgimento da Teoria dos Contratos e o problema do Agente-Principal.

Murphy e Jensen (1990) analisaram a remuneração de mais de 2.000 CEO's por um período de mais de 5 décadas. No estudo eles observaram que a relação entre remuneração e performance era muito baixa no mundo corporativo e que, inclusive, essa relação havia caído ao longo dos 50 anos anteriores. Os autores encontraram que, em média, uma alteração de US\$1.000,00 na riqueza dos acionistas correspondia a um aumento no bônus do ano corrente e do ano seguinte do executivo no montante de apenas US\$ 0,02. O valor das stock options desses executivos variava US\$ 0,15 para cada aumento de US\$1.000,00 na riqueza dos acionistas.

Os autores identificaram ainda que, apesar de uma parcela relevante da remuneração dos executivos ser proveniente de remunerações variáveis (na amostra, representavam cerca de 50\% da remuneração anual total dos executivos), essa remuneração não era muito sensível às diversas medidas de performance analisadas, como mudança no valor das ações, lucro contábil ou receita das companhias. Uma das possibilidades identificadas pelos autores para a baixa relação entre a remuneração dos executivos e a performance das companhias é a possibilidade de haver forças políticas tanto no setor público quanto no privado, limitando uma remuneração excessiva devido a resultados extraordinários.

Motivados por esses resultados, os mesmos autores publicaram um artigo (também em 1990) intitulado de “CEO Incentives - It's Not How Much You Pay, But How" que endereça exatamente essa questão. Na ocasião, para os CEO's das então 250 maiores empresas dos EUA, os autores encontraram uma relação muito 
baixa entre as duas variáveis, de forma que um retorno de US\$1.000,00 para os acionistas representava uma variação de apenas US\$ 0,067. Os resultados foram estatisticamente significantes, mas em termos econômicos apresentaram pouca relevância.

Os autores endereçaram também a possibilidade de os CEO's serem motivados por fatores que não sejam apenas financeiros, como poder, prestígio ou visibilidade pública. Segundo os autores, esses fatores afetam a remuneração necessária para atrair talentos, mas para que sirvam de ferramenta para alinhar os interesses dos executivos e dos acionistas, esses incentivos não-monetários precisam variar de acordo com a performance da companhia. Normalmente incentivos não-monetárias são difíceis de serem atrelados a uma variação da performance da companhia. Segundo os autores, incentivos monetários e participações societárias são as ferramentas mais eficientes para alinhar os interesses dos executivos e dos acionistas.

Com base nos resultados de Murphy e Jensen (1990), Hall e Liebman (1997) realizaram um estudo utilizando dados de painéis para um período de 15 anos e utilizaram uma forma de remuneração mais ampla para a amostra, incluindo a variação no valor das ações e a variação no valor das stock options detidas pelos CEO's. Os autores argumentam que, ao contrário dos resultados encontrados por Murphy e Jensen (1990), a remuneração dos CEO’s está altamente relacionada à performance das companhias, encontrando uma sensibilidade para a relação entre remuneração e performance positiva e estatisticamente significante, e economicamente relevante.

Os autores mostram que, na amostra utilizada, a remuneração anual média de um CEO numa empresa que se encontra no $30^{\circ}$ percentil de performance (para o período estudado, foram empresas com retornos anuais médios de $-7 \%$ ) é de US\$ 1 milhão, enquanto que, a remuneração anual média de um CEO de uma empresa que se encontra no $70^{\circ}$ percentil de performance (retornos anuais médios de $20.5 \%$ para o período estudado) é de US\$ 5 milhões - o que representa uma diferença significativa entre CEO's que atingiram uma remuneração significativamente acima da média em relação a CEO's que atingiram uma remuneração significativamente abaixo da média. 
O estudo argumenta que, o motivo pelo qual seus resultados diferem dos encontrados anteriormente por Murphy e Jensen (1990) é que eles incluíram a variação no valor das ações e das stock options detidas pelos CEO's, e que a remuneração baseada em ações se tornou a principal forma de remuneração dos CEO's nos Estados Unidos ao longo do período estudado, ao passo que a amostra utilizada por Murphy e Jensen foi extraída de um período anterior (1969-1983), onde não havia ocorrido ainda esse aumento na utilização de ações como forma de remuneração, que ocorreu ao longo do anos 80 e 90. Dessa forma, a maior parte da sensibilidade entre remuneração e performance encontrada pelos autores vem exatamente da remuneração baseada em ações - salários e bônus anuais de fato apresentaram pouca sensibilidade à performance na amostra estudada pelos autores.

Além disso, os autores argumentam também que a forma como Murphy e Jensen medem a sensibilidade entre remuneração e performance pode parecer "enganosa" quando a base do cálculo (o valor da empresa) for muito grande. Nesses casos, mesmo que o executivo receba uma remuneração elevada por uma boa performance da companhia, a variação no valor das ações seria tão alta que a sensibilidade seria pequena.

De forma a endereçar essa questão, Aggarwal e Samwich (1998) mostram que a sensibilidade entre remuneração e performance cai com a volatilidade da performance da companhia - empresas com maior volatilidade no preço das ações tendem a ter uma sensibilidade menor entre remuneração e performance.

Segundo as conclusões do estudo, focar na relação média entre remuneração e performance para um grupo heterogêneo de empresas dificulta as conclusões dado que existe também uma heterogeneidade nas sensibilidades entre remuneração e performance. Ao incluir a variância no preço das ações como fator para controlar essa heterogeneidade, os autores chegam à conclusão de que a sensibilidade entre remuneração e performance cai de acordo com o risco (ou volatilidade) na performance das companhias. No nível máximo de variância na amostra utilizada, a sensibilidade entre remuneração e performance é de US\$1,45 para cada US\$1.000,00 de performance (medida como a variação no preço das ações) atingida para a companhia. Ao nível médio de variância, essa sensibilidade 
sobe para US\$ 14,52 em remuneração para o executivo para cada U\$ $1.000,00$ de performance atingida para a companhia.

Os autores argumentam que seus resultados são consistentes com a teoria do agente-principal, e que os fundamentos dessa teoria são levados em consideração e incorporados nos contratos de remuneração dos executivos.

Clementi e Cooley (2009) utilizam uma amostra mais recente - de 1993 a 2006 - para analisar a relação entre remuneração e performance. A definição de remuneração utilizada pelos autores difere daquela utilizada por Murphy e Jensen e se aproxima mais da definição utilizada por Hall e Liebman. Os autores definiram como medida de remuneração dos executivos, a variação no patrimônio dos executivos, que esteja relacionado à sua atividade como administrador da empresa, ou seja, a soma da remuneração fixa, da remuneração variável paga em bônus, da remuneração baseada em ações, e da variação no valor das ações e stock options detidas pelo executivo.

Alguns dos resultados importantes encontrados pelos autores foram o fato de que a distribuição da remuneração dos executivos é extremamente assimétrica, o que faz com que conclusões a partir das médias sejam enganosas, e o fato de que, em todos os anos da amostra, uma parcela relevante dos CEO's "perderam dinheiro" com sua remuneração anual (apresentaram uma variação patrimonial negativa quando levado em conta a variação no valor das ações e stock options detidas por eles).

Os autores concluíram ainda que, independente do critério utilizado para se medir a performance das companhias, a remuneração dos executivos apresentava uma resposta significativa à variação do patrimônio dos acionistas. Os autores também expõem o fato de que a adoção da remuneração baseada em ações apresentou um grande crescimento ao longo das décadas de 90 e 2000, o que colabora para a conclusão anterior.

Nesse sentido, por utilizar a variação do valor das ações e stock options sob posse dos executivos como medida de remuneração, os resultados encontrados por Clementi e Cooley se aproximam dos resultados encontrados por Hall e Liebman, no sentido de que em ambos os estudos, os autores encontraram 
relações, não só estatisticamente, mas economicamente significativas entre remuneração e performance.

No Brasil, por sua vez, o número de trabalhos sobre remuneração de executivos ainda é pequeno quando comparado à literatura internacional, em função, principalmente, da menor disponibilidade de informações. Além disso, na maior parte dos estudos no Brasil, a performance (financeiro e/ou de mercado) é tratada como variável dependente a ser explicada pela remuneração dos executivos, o que difere da abordagem utilizada no presente estudo, onde a remuneração dos executivos é a variável dependente e a performance das companhias é a variável explicativa.

Nesse sentido, Carvalhal da Silva e Chien (2014) analisaram a relação entre remuneração e performance nas companhias abertas brasileiras, utilizando como amostra 420 companhias abertas ao longo do período de 2002 a 2009. Os autores não identificaram em seus trabalhos qualquer relação estatisticamente significante entre remuneração e performance (seja performance de mercado ou financeira), ou seja, empresas que pagam mais a seus executivos não possuem maior valor de mercado ou apresentam melhor desempenho operacional

Pinto e Leal (2013) analisaram a relação entre concentração societária e a remuneração dos executivos nas companhias abertas no Brasil. Os resultados encontrados pelos autores estão de acordo com a hipótese de que firmas com menor grau de concentração tendem a pagar salários maiores a seus executivos e membros do conselho. De acordo com os resultados encontrados pelos autores, os executivos em empresas com menor grau de concentração, recebem em média $79 \%$ acima da remuneração de executivos nas empresas com um grupo de controle definido (porém, a remuneração de executivos pertencentes ao grupo de controle ou membros de suas famílias, também é mais alta nas empresas com um grupo de controle definido).

Aguiar e Pimentel (2017) analisam a relação entre remuneração e performance tratando a remuneração tanto como variável dependente quanto explicativa. Os autores utilizaram quase que a totalidade das empresas listadas na BM\&F Bovespa em sua amostra (representando $98 \%$ da capitalização total de 
mercado da BM\&F Bovespa em 2015) para o período de 2011 a 2015. Seus resultados sugerem que existe uma relação de bi-causalidade, positiva e estatisticamente significante, para a relação entre remuneração e performance (tanto para performance financeira, quanto para performance de mercado). 


\section{Fundamentos Teóricos}

\subsection{Histórico}

Dentre os tópicos que envolvem os diversos aspectos de governança corporativa, a remuneração de executivos é um dos que recebe maior atenção. Os estudos acadêmicos sobre a remuneração de executivos passaram a receber muita atenção a partir dos anos 80, principalmente nos Estados Unidos. Os investidores, cada vez mais, demandam mais transparência das instituições e maior alinhamento de interesses entre os executivos e os acionistas e, em tese, a remuneração dos executivos é um dos principais instrumentos para alinhar estes interesses.

Os debates sobre a remuneração de executivos sempre tiveram grande espaço na mídia. Por diversas vezes, a alta remuneração de executivos recebeu muita atenção em campanhas de políticos com discursos populistas, que enfatizavam a diferença discrepante entre a remuneração destes executivos e os salários na base da pirâmide corporativa.

Principalmente nos Estados Unidos, este crescente gap recebeu grande atenção da mídia e foi alvo de ataques populistas em diferentes períodos da história: foi o caso nos anos 80, durante os "Excesses of the Eighties", onde altos salários foram muitas vezes associados a demissões em massa; nos anos 90 com o boom do mercado acionário e as altas remunerações atreladas a ações; e também nos anos 2000 com os bônus milionários pagos a executivos à frente de instituições envolvidas com os empréstimos Subprime durante a crise de 2008.

Independente dos montantes pagos aos executivos, em termos econômicos a questão mais importante não é o quanto os executivos são pagos, mas sim como eles são remunerados. Para que haja um alinhamento de interesses entre o executivo e os acionistas, o primeiro deve ser remunerado de acordo com os retornos proporcionados ao segundo, ou seja: a remuneração do executivo deveria estar intrinsecamente relacionada à variação do patrimônio dos acionistas, de 
forma que deveríamos encontrar uma relação positiva e estatisticamente significante entre a remuneração dos executivos e a performance das companhias.

O fundamento teórico por trás dessa relação remete ao problema do Agente-Principal, muito debatido na Teoria dos Contratos, e também à relação risco x retorno, axiomática nos estudos de finanças.

\subsubsection{Teoria do Agente-Principal}

Os artigos acadêmicos sobre remuneração de executivos passaram a receber mais atenção a partir da década de 80 , ao mesmo tempo em que também houve avanços significativos nos estudos sobre Teoria dos Contratos.

Em um problema clássico de um contrato, um principal contrata um agente para agir em seu interesse, mas devido a uma assimetria de informações o principal não consegue observar diretamente as ações do agente, de forma que este pode agir em seu próprio interesse, aumentando seu payoff e reduzindo o payoff do principal, criando um problema de moral-hazard (ou risco moral).

No mundo corporativo, esse problema é muito comum na medida em que os conselhos de administração, representando os interesses dos acionistas, elegem administradores para gerir suas empresas. Estes administradores, por não serem sócios ou apresentar uma participação pouco relevante na composição acionária na maior parte dos casos, podem tomar decisões que tendem a beneficiar seus próprios interesses e ir contra o interesse dos acionistas.

A premissa básica por trás da Teoria dos Contratos, é que os indivíduos respondem a incentivos materiais. De forma a alinhar os interesses da administração da companhia (na figura do agente) e dos acionistas (na figura do principal), são oferecidos pacotes de remuneração que fazem com que os administradores sejam remunerados de acordo com sua performance. As medidas de performance costumam variar, mas medidas contábeis como a Receita, EBITDA (Earnings Before Interest, Taxes, Depreciation and Amortization - lucro antes dos juros, impostos, depreciação e amortização) ou Lucro Líquido e o 
rendimento das ações são frequentemente utilizadas como medidas de performance.

Uma das críticas a essas medidas é que elas dependem de diversos fatores que estão além do controle dos executivos, de forma que a companhia pode vir a obter uma boa performance (seja ela qual for a medida de performance utilizada) por um fator de sorte, que não tenha sido fruto do poder de execução da administração da companhia, sendo o inverso também verdadeiro - a companhia pode vir a ter uma performance ruim por fatores externos, apesar de um bom trabalho de gestão da administração da companhia.

Para uma leitura mais detalhada sobre o problema do Agente-Principal, inerente na elaboração de contratos, o artigo "The Theory of Contracts" de 1986, dos autores Oliver Hart e Bengt Holmstrom, traz um estudo profundo sobre teoria dos contratos.

\subsubsection{Relação Risco-Retorno}

Assim como na aquisição de qualquer ativo, a relação risco-retorno deve prevalecer na remuneração de executivos, de forma que ocupar um cargo de alta responsabilidade deveria estar associado a uma alta remuneração. No que concerne à responsabilidade dos diretores estatutários, a Lei 6.404/76 ("Lei das S.A.”), em seu artigo 158 estabelece as hipóteses em que o Diretor poderá ser responsabilizado civilmente por atos praticados pela administração da companhia. O referido artigo implementa o Regime de Responsabilidade Solidária entre os administradores da companhia, de forma que os diretores estatutários passam a responder por ações da companhia (e não apenas por suas próprias ações e/ou omissões) em diversos casos.

Se o executivo será penalizado com o fracasso - seja ele responsável ou não pelo motivo que tenha levado a companhia ao fracasso - então ele também deve ser remunerado de acordo, caso obtenha sucesso. Se o executivo não for bem remunerado em caso de sucesso, tenderá a minimizar seu risco e, consequentemente, influenciará a performance da companhia de forma negativa. 
Em seu artigo "Executive Compensation" de 1999 (e baseado nos estudos de Holmstrom e Hart), Murphy define a relação entre risco e a remuneração dos executivos da seguinte forma: suponha que o valor da firma é determinado por $\mathrm{x}$, tal que $x=e+\varepsilon$, onde $e$ é o esforço despendido pelo executivo para aumentar o valor da firma e $\varepsilon$ é o ruído que representa fatores que não estão sobre o controle do executivo mas afetam o valor da firma, e que o ruído apresenta uma distribuição Normal $\varepsilon \approx N\left(0, \sigma^{2}\right)$. Suponha ainda que o contrato com o executivo assuma a forma $w(x)=s+b x$, onde $s$ é um salário fixo e $b$ é a sensibilidade entre remuneração e performance (ou seja, representa o quanto o executivo será remunerado para cada incremento gerado no valor da firma).

Assumindo que o executivo apresenta utilidade exponencial expressa por $U(x)=-e^{r(W-c(e))}$, onde $r$ é o coeficiente de aversão a risco do executivo e $c(e)$ é a função convexa de "desutilidade" do esforço do executivo, Murphy define a relação ótima entre remuneração e performance pela equação:

$$
b=\frac{1}{1+r \sigma^{2} c^{\prime \prime}}
$$

A equação (1) acima implica que a relação ótima entre remuneração e performance será igual a 1 (ou seja, para cada $\mathrm{R} \$ 1$ gerado para o acionista, o executivo deveria ser remunerado em $\mathrm{R} \$ 1$ também) quando o resultado da performance for pré-definido de forma que a variação da performance seja igual a zero $\left(\sigma^{2}=0\right)$, ou quando o executivo for neutro ao risco $(r=0)$. A equação também determina que os incentivos serão mais fracos para executivos mais avessos ao risco $(\partial \mathrm{b} / \partial \mathrm{r}<0)$, e também serão mais fracos o quão maior for o ruído $\varepsilon$, ou os fatores externos que influenciam o valor da firma $(\partial \mathrm{b} / \partial \sigma 2<0)$. 


\section{$4 \quad$ Base de Dados/Metodologia}

O objetivo desse estudo é identificar as práticas de remuneração adotadas para os executivos no Brasil e medir a relação entre a performance das companhias e a remuneração desses executivos. Conforme mencionado na seção 3, para que haja um alinhamento de interesse entre os sócios e os executivos, visando mitigar o problema do agente-principal, deveríamos encontrar uma relação causal entre a performance das companhias e a remuneração dos executivos, de forma que, o quão maior a performance obtida, maior deveria ser a remuneração anual destes executivos.

Foi utilizado como base de dados os Formulários de Referência, divulgados anualmente à CVM (Comissão de Valores Mobiliários) pelas Companhias de capital aberto, e as bases de dados da Reuters e Bloomberg para os dados de performance das companhias (seja essa performance medida pela variação do preço das ações assim como as medidas contábeis utilizadas neste estudo) e medidas indicativas de tamanho das empresas tais como o valor patrimonial ou a volatilidade implícita destas.

Todos os dados foram corrigidos pela inflação, aos preços do ano base de 2015, utilizando o IPCA extraído do site do IBGE.

\subsection{Dados de Remuneração dos Executivos}

O estudo foi feito com base nas empresas integrantes do Novo Mercado, segmento especial de negociação de valores mobiliários da BM\&F Bovespa que estabelece padrões de governança corporativa diferenciados, sendo o segmento com o mais alto padrão de transparência e práticas de governança na $B M \& F$ Bovespa.

Dos diversos pilares da governança corporativa, a remuneração dos executivos é um dos que vem recebendo maior destaque. Segundo o IBGC (Instituto Brasileiro de Governança Corporativa), os princípios e boas práticas de 
governança corporativa podem ser desenvolvidos de diversas formas, dentre as quais se inclui a gestão da remuneração executiva.

Nesse sentido, as empresas com as melhores práticas de governança corporativa, em tese, devem adotar as práticas de remuneração que tragam maior alinhamento entre remuneração e performance, endereçando o problema do agente-principal. Como o Novo Mercado é o segmento de listagem da BM\&F Bovespa com as melhores práticas de governança corporativa, utilizamos as empresas listadas nesse segmento como base para nosso estudo.

Foi utilizado como base para o estudo as empresas que faziam parte deste segmento no ano base de 2015 e buscamos todos os dados de remuneração dos executivos para essas companhias desde o ano base de 2009. O motivo para utilização desse intervalo é que somente a partir de 2009 as companhias de capital aberto passaram a serem obrigadas a divulgar a remuneração de seus executivos anualmente através dos Formulários de Referência.

Em 7 de dezembro de 2009 a CVM (Comissão de Valores Mobiliários) tornou público a aprovação da instrução iCVM 480 que dispõe sobre o registro de emissores de valores mobiliários admitidos à negociação em mercados regulamentados de valores mobiliários. Conforme estabelece o artigo 24 , inciso $\S$ $1^{\text {o }}$ da referida instrução, "os emissores de valores mobiliários devem entregar o formulário de referência atualizado anualmente, em até 5 (cinco) meses contados da data de encerramento do exercício social".

O conteúdo completo dos formulários de referência encontra-se no anexo 24 da iCVM 480. Dentre outras informações, o formulário de referência contém a composição da remuneração da diretoria estatutária das companhias, segregado em:

(i) Remuneração fixa anual;

(ii) Remuneração variável;

(iii) Benefícios pós emprego;

(iv) Benefícios motivados pela cessação do exercício do cargo;

(v) Remuneração baseada em ações, incluindo opções; 
Para fins deste estudo, os componentes (iii) e (iv) da remuneração dos executivos listados acima foram agrupados em um único componente de Remuneração Pós-emprego. A seção 5 abaixo descreve com mais detalhes cada um dos componentes de remuneração utilizados neste estudo.

Foi considerado apenas a remuneração da diretoria estatutária, dado que os formulários de referência divulgam apenas a remuneração global da diretoria estatutária. Vale mencionar que os estudos internacionais sobre remuneração de executivos costumam ser voltados para a remuneração do CEO apenas, já que nos EUA é divulgado anualmente a remuneração individual por executivo, prática que vem sendo adotada há décadas, ao passo que no Brasil é divulgada apenas a remuneração global da diretoria estatutária, o que vem sendo feito desde 2009. Dessa forma, há também uma grande diferença no tamanho da amostra utilizada quando comparada aos estudos internacionais já realizados.

\subsection{Dados de Performance das Companhias}

Os dados de performance foram extraídos das bases de dados da Reuters e da Bloomberg. Foram utilizados como dados de performance:

(i) Variação no patrimônio dos acionistas, medida como Market Cap $_{t-1} \times$ Retorno sobre o investimento ${ }_{t}$, onde Market Cap representa o valor das ações da empresa e Retorno sobre o investimento representa o retorno total obtido com o investimento nas ações naquele ano. Os dados de Market Cap e de Retorno sobre o Investimento foram extraídos da base de dados da Reuters. A seção 7.1 descreve esse cálculo com mais detalhes;

(ii) Book Value, que é o valor patrimonial contábil das empresas, utilizado e descrito com mais detalhes na seção 7.2. Os dados de Book Value foram extraídos da base de dados da Bloomberg.

(iii) Variância das ações, utilizado como medida de volatilidade para calcular o risco atrelado às ações de cada companhia da amostra. Essa medida de risco é calculada como o desvio padrão anualizado da variação logarítmica diária 
do preço das ações. Esses dados foram extraídos da base de dados da Bloomberg e são utilizados na seção 7.2.2;

(iv) Receita Líquida, que é calculado como as vendas brutas da companhia, reduzidas de devoluções, descontos e impostos sobre a receita. Os dados de Receita Líquida foram extraídos da base de dados da Reuters e são utilizados como medida de performance na seção 7.3.1;

(v) EBITDA, que representa o lucro da companhia, antes de descontados o resultado financeiro, os impostos sobre o lucro e a depreciação e amortização. Os dados de EBITDA foram extraídos da base de dados da Reuters e são utilizados como medida de performance na seção 7.3.2;

(vi) Lucro Líquido, representa a última linha da Demonstração de Resultados do Exercício (DRE) da companhia, já excluindo a distribuição de dividendos preferenciais. Os dados de Lucro Líquido foram extraídos da base de dados da Reuters e são utilizados como medida de performance na seção 7.3.3; 


\section{Os Componentes da Remuneração dos Executivos}

Essa seção tem como objetivo descrever os diversos componentes da remuneração anual de um executivo. Os componentes descritos nesta seção serão utilizados ao longo deste estudo para as regressões que irão medir a relação entre remuneração dos executivos e a performance das companhias.

Segundo estudo elaborado pela PwC (PricewaterhouseCoopers) ${ }^{1}$ em 2015, o modelo de remuneração dos executivos nas companhias de capital aberto no Brasil tem se aproximado cada vez mais dos padrões internacionais, incluindo componentes de remuneração de longo prazo, mecanismos que alinham remuneração a performance, e mecanismos de governança que geram maior transparência tornando público os dados de remuneração dos principais executivos (mais especificamente, da diretoria estatutária).

Em resumo, o referido estudo da PwC mostra que o modelo de remuneração executiva no Brasil apresenta os mesmos componentes dos modelos de remuneração internacionais, porém com uma ênfase maior na remuneração fixa e na remuneração variável de curto prazo na maior parte dos casos.

Conforme mencionado na seção 4.1 acima, dividimos a remuneração anual dos executivos nos 4 componentes abaixo:

\section{(i) Remuneração fixa anual}

Corresponde à parcela da remuneração base dos executivos, pago mensalmente, independente de performance - salário mensal. Segundo Murphy (1999), os executivos costumam dar grande valor ao salário mensal ao aceitar ou declinar uma oferta de emprego, mesmo considerando o fato de que a

\footnotetext{
${ }^{1}$ Price Waterhouse Coopers e FGV EAESP (2015): "Remuneração Executiva e Geração de Valor Práticas de Remuneração e Desempenho em Empresas de Capital Aberto no Brasil”.
} 
remuneração fixa representa, cada vez mais, uma parcela menor da remuneração total dos executivos nos padrões internacionais.

Alguns dos motivos para isso são o fato de que a remuneração fixa, em muitos casos, acaba servindo de base para definir a remuneração variável (que pode ser estabelecida em termos de múltiplos de salários), e o fato de que o executivo mais avesso ao risco irá preferir um salário fixo maior em detrimento de uma política de remuneração variável mais agressiva.

O estudo da PwC mencionado no início desta seção foi realizado com base em 62 empresas listadas na Bovespa no segmento do Novo Mercado. Segundo o estudo, $87 \%$ das empresas consultadas informaram que o principal critério para definição da remuneração fixa de um executivo são as pesquisas de mercado. Normalmente essas pesquisas são realizadas entre empresas da mesma indústria ou entre empresas de tamanhos similares.

\section{(ii) Remuneração variável}

A remuneração variável corresponde aos bônus pagos aos executivos, normalmente com base em alguma métrica de performance de curto prazo, com periodicidade semestral ou anual, a critério da administração da companhia. No estudo realizado pelo $\mathrm{PwC}$, mencionado no item (i) acima, 60 das 62 empresas entrevistadas confirmaram adotar uma política de remuneração variável de curto prazo, mostrando que, assim como nos padrões internacionais, a maior parte das empresas apresentam uma política de remuneração variável de curto prazo também no Brasil. Os critérios de elegibilidade para o recebimento de bônus anual (ou semestral) costumam variar muito entre as empresas de diferentes tamanhos e indústrias, podendo ser restrito somente à diretoria estatutária, quanto até abranger todos os funcionários da empresa.

Existe uma grande heterogeneidade nas políticas de remuneração variável de curto prazo, tanto nos padrões internacionais quanto no Brasil, mas na maior

parte dos casos, as remunerações variáveis de curto prazo costumam ter um componente de avaliação individual, e um relacionado à equipe ou à empresa como um todo. Além disso, a maioria das empresas também adota algum critério 
econômico/financeiro para a determinação do bônus, e algum critério discricionário que engloba avaliações de desempenho individuais ou avaliações de performance relativas a algum objetivo estratégico pré-estabelecido.

No estudo realizado pela PwC, 58\% das empresas responderam utilizar alguma forma de avaliação de desempenho para definição dos bônus, e $48 \%$ das empresas responderam utilizar o EBITDA como medida contábil para balizar a remuneração variável - sendo EBITDA a medida econômica/financeira mais utilizada para esse fim dentre as empresas consultadas.

Com relação aos indicadores de performance de natureza não financeira, dentre a amostra consultada, as empresas declararam equilibrar indicadores quantitativos de performance (com metas individuais e coletivas) e qualitativos (avaliações individuais, mais subjetivas).

\section{(iii) Remuneração pós emprego}

A remuneração pós emprego inclui os benefícios a serem pagos ao executivo após o período em que esteve na administração da companhia. Algumas empresas apresentam também acordos com alguns executivos relativo a uma remuneração caso ele seja desligado da companhia. Esse tipo de remuneração é chamado de "Golden Parachute".

Esse tipo de remuneração representa uma parcela muito pequena da remuneração total paga aos executivos no período estudado. No período de 2009 a 2015, para uma amostra variando de 101 a 128 empresas (dependendo do ano), a remuneração pós-emprego média representou entre $1 \%$ e $4 \%$ da remuneração total paga aos executivos, conforme exibido na Figura 1.

\section{(iv) Remuneração baseada em ações}

A remuneração baseada em ações é a principal forma de remuneração baseada em incentivos de longo prazo. Embora a remuneração variável de curto prazo ainda seja muito relevante no Brasil, as políticas de remuneração de longo 
prazo vêm ganhando cada vez mais relevância nos últimos anos. No estudo realizado pela PwC mencionado nos itens (i) e (ii) acima, 46 das 62 empresas entrevistadas ofereciam pacotes de remuneração de longo prazo e estes eram, em média, responsáveis por $21 \%$ da remuneração paga aos executivos ${ }^{2}$.

Algumas das formas mais comuns de reter os executivos com uma remuneração baseada em ações são:

- $\quad$ Planos de Stock Options. Stock Options são contratos celebrados entre a empresa e o executivo onde o segundo ganha a opção de comprar ações a um preço de exercício pré-estabelecido ("strike price”), durante um período de tempo também pré-estabelecido. Os Stock Options dos executivos se tornam exercíveis ("vested") depois de algum período de trabalho do executivo na companhia.

- $\quad$ Phantom Stocks. São ações "virtuais", por meio das quais os executivos recebem um prêmio atrelado à valorização dessas ações em determinado período de tempo.

- $\quad$ Ações restritas (Restricted Stocks). São outorgadas ações aos executivos elegíveis ao plano de outorga de ações restritas. Essas ações são adquiridas pelos executivos elegíveis (normalmente com algum desconto) sobre determinadas condições. Essas condições costumam ser relacionadas ao tempo de permanência do executivo no cargo e a algum indicador de performance pré-estabelecido.

Conforme exposto no estudo realizado pela $\mathrm{PwC}$, dentre as empresas que mencionaram adotar planos de remuneração de longo prazo baseado em ações, 91\% das empresas declararam conceder planos de Stock Options como incentivos de longo prazo; $4 \%$ adotam planos de incentivos de longo prazo baseado em ações no formato de Phantom Stocks; 2\% informaram ceder ações baseados no cumprimento de metas de desempenho; e 9\% informaram utilizar mais de um tipo de incentivo de longo prazo através de remuneração baseada em ações.

\footnotetext{
${ }^{2}$ Dado referente ao exercício social de 2013.
} 
Os diversos tipos de remuneração com base em ações têm como objetivo dar maior alinhamento entre os interesses dos executivos e dos acionistas, em um horizonte de longo prazo.

Além dos componentes mencionados, os executivos também recebem remuneração por meio de benefícios tais como assistência médico-hospitalar, seguro de vida, previdência privada, alimentação, automóvel, telefone celular, entre outros.

Vale mencionar que os componentes de remuneração pós emprego e remuneração baseada em ações podem gerar ruídos dado que, em muitos casos, por definição não estão atrelados à performance dos executivos. No caso da remuneração pós emprego, esse efeito apesar de ser mais claro (dado que na maior parte dos casos são obrigações contratuais que não estão relacionados à performance dos executivos, como o caso dos Golden Parachutes, citados no item (iii) desta seção), acaba sendo muito pequeno e pouco relevante para nossos estudos devido à representatividade da remuneração pós emprego em relação à remuneração anual total.

Para o caso da remuneração baseada em ações, o ruído ocorre no sentido de que, para as remunerações advindas dos planos de stock options, o que é registrado nos formulários de referência são os valores das opções que foram vested (que se tornaram elegíveis a serem exercidas), e não das opções que foram granted (que foram concedidas) naquele ano. Nesse sentido, pode haver um lag muito grande entre o momento em que o executivo foi "recompensado" por sua performance (o momento em que foram granted as stock options), e o momento em que essa recompensa foi registrada no formulário de referência. E, ao contrário do que ocorre com a remuneração pós emprego, a remuneração baseada em ações pode ser bem relevante na remuneração anual total do executivo, chegando muitas vezes a representar mais de $50 \%$ da remuneração anual total do executivo.

Para uma descrição mais detalhada de todos os componentes da remuneração dos executivos, o artigo de 1999, "Executive Compensation" de Kevin J. Murphy, traz uma descrição bem rica dos diversos componentes citados. 


\section{Variação da Remuneração Entre as Empresas}

Os padrões de remuneração de executivos costumam variar bastante entre as empresas, porém, apesar da heterogeneidade, os componentes de remuneração dos executivos costumam se basear em uma remuneração fixa mensal, uma remuneração variável de curto prazo e uma remuneração variável de longo prazo, normalmente baseada em ações. A seção 5 acima descreve com mais detalhes os principais componentes de remuneração dos executivos.

A Figura 1, presente no anexo 1, mostra a evolução da participação de cada componente da remuneração total da diretoria estatutária para as empresas listadas no Novo Mercado, de 2009 a 2015, tanto em termos absolutos, quanto em termos percentuais. Podemos observar que há uma tendência de aumento da participação da remuneração fixa no total da remuneração dos executivos, ao contrário do que observamos nos padrões internacionais, onde a remuneração variável vem ganhando maior representatividade na remuneração total.

A Figura 2, presente no anexo 1, traz a evolução da participação de cada componente da remuneração total da diretoria estatutária, ao longo do mesmo período, para o grupo das empresas integrantes do primeiro e do último quartis das empresas listadas por tamanho (sendo o tamanho medido em termos de market cap). Podemos observar que, para o primeiro quartil (para as empresas maiores), a remuneração fixa representa um percentual menor da remuneração total, variando entre $28 \%$ e $40 \%$ da remuneração total dos executivos. Já para as empresas do último quartil (para as empresas menores), a remuneração fixa representa entre $51 \%$ e $70 \%$ da remuneração total ao longo do período estudado.

Um dos motivos que poderia explicar o aumento da participação da remuneração fixa na remuneração total dos executivos é o fato de que, ao longo do período estudado, o iBovespa proporcionou retornos negativos todos os anos, com exceção de 2009. A performance negativa ao longo desses anos faz com que tanto a remuneração variável de curto prazo, quanto a remuneração baseada em 
ações sejam menores ao longo desse período, consequentemente aumentando o percentual da remuneração fixa no total da remuneração da diretoria estatutária.

Além da heterogeneidade devido ao tamanho das empresas, existe também uma heterogeneidade por setor da economia. Os gráficos da Figura 3, presente no anexo 1, mostram a evolução da participação de cada componente da remuneração total da diretoria estatutária, dividido por indústria. As indústrias escolhidas para essa segmentação foram: (i) Financeiro; (ii) Educação; (iii) Imobiliário; (iv) Consumo Cíclico; (v) Consumo não-cíclico; (vi) Utilidade Pública; (vii) Transporte; e (viii) Outros. A classificação setorial foi feita conforme a classificação divulgada pela BM\&F Bovespa, e os setores selecionados foram aqueles com maior representatividade em número de empresas, ou com alguma característica específica relevante.

Podemos observar pelos gráficos que o perfil de remuneração varia bastante de indústria para indústria. Um caso particular dentre os setores apresentados é o setor de Educação. O setor de Educação gerou um retorno muito bom para os acionistas ao longo do período citado. Podemos observar pelos gráficos que a remuneração dos executivos aumentou bastante ao longo desse período, sendo a principal forma de remuneração a baseada em ações - em 2009, a remuneração com base em ações representou $16 \%$ da remuneração total do setor, ao passo que em 2015, representou cerca de $66 \%$ da remuneração total. 


\section{Relação Entre Remuneração e Performance}

Com base nos fundamentos expostos nas seções anteriores, nessa seção iremos estimar a relação entre a remuneração dos executivos e a performance das companhias. Vale ressaltar que os diferentes estudos acadêmicos que estimam essa relação trabalham com variáveis absolutas em alguns casos (como os estudos de Jensen e Murphy (1990), Murphy (1999) e Clementi e Cooley (2009)) ou logarítmicas em outros (como os estudos de Hall e Liebman (1997) e Clementi e Cooley (2009), que utiliza tanto variáveis absolutas como logarítmicas para suas regressões). Essas escolhas determinam se o coeficiente estimado na regressão (aqui representado como $\beta$ ) irá representar a sensibilidade da relação entre remuneração e performance, ou a elasticidade dessa relação. Neste estudo iremos estimar a sensibilidade dessa relação utilizando, portanto, variações absolutas tanto nas variáveis dependentes - que serão as medidas de remuneração dos executivos - quanto nas independentes - que serão as diferentes medidas de performance.

Portanto, os $\beta$ `s nas regressões abaixo representam a sensibilidade da relação entre remuneração e performance - o $\beta$ representa a variação, em Reais, na remuneração dos executivos para cada Real de performance (seja essa performance a variação no patrimônio dos acionistas ou alguma medida de performance contábil conforme explicado nas subseções abaixo). O motivo para a escolha de variáveis absolutas ao invés de logarítmicas é a facilidade de interpretação econômica, na medida em que trabalhamos com retornos absolutos ao acionista (seja em relação ao valor de suas ações ou em métricas contábeis), e a remuneração absoluta recebida em contrapartida pelos executivos. 


\subsection{Relação entre remuneração dos executivos e a variação no patrimônio dos acionistas}

Nesta subseção, estimamos a relação entre os diversos componentes de remuneração dos executivos e performance medida como a variação no patrimônio dos acionistas. A sensibilidade da relação entre remuneração e performance, ou os $\beta$ 's, nas regressões realizadas representam a variação na remuneração dos executivos, em Reais, para cada $\mathrm{R} \$ 1,00$ de variação no patrimônio dos acionistas. A variação no patrimônio dos acionistas é medida como:

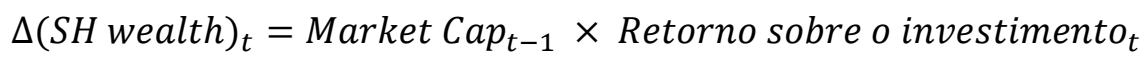

Onde Market Cap representa o valor das ações da empresa (o preço da ação no final do ano multiplicado pelo número de ações da companhia em circulação), e Retorno sobre o investimento representa o retorno total obtido com o investimento nas ações naquele ano, calculado como a variação no preço das ações acrescentado do retorno proporcionado pelos dividendos distribuídos pela companhia naquele ano, conforme representado pela seguinte equação:

$$
\text { Retorno sobre o investimento }=\left(\frac{\text { Preço }_{t}+\text { Dividendos }_{t}}{\text { Preço }_{t-1}}-1\right) \times 100
$$

Estimamos os $\beta$ 's para a seguinte regressão:

$$
\Delta(\text { Remuneração })_{t}=\alpha+\beta \Delta(S H \text { wealth })_{t}
$$

onde, a variável explicada Remuneração é dividida entre (i) Remuneração Fixa, (ii) Remuneração Variável, (iii) Remuneração Baseada em Ações, e (iv) Remuneração Total, que inclui a soma de toda a remuneração da diretoria estatutária em cada ano, e a variável explicativa " $\Delta(S H \text { wealth })_{t}$ " representa a variação no patrimônio dos acionistas, conforme explicado acima. Os resultados da regressão expressa pela equação (2) são apresentados na tabela 1, presente no anexo 2. 
De acordo com a teoria exposta, deveríamos observar uma relação positiva e estatisticamente significante entre, tanto os componentes de remuneração variável quanto a remuneração total da diretoria estatutária, e a performance da companhia. No entanto, não observamos uma relação estatisticamente significante entre nenhum dos componentes de remuneração e a performance da companhia (medida, nesse caso, como a variação do patrimônio dos acionistas) a um nível de significância de $5 \%$.

Ao controlarmos os efeitos fixos para o Cross-section, observamos que existe uma relação positiva e estatisticamente significante apenas para o componente de remuneração fixa e performance a um nível de significância de $5 \%$.

De acordo com a teoria, o componente de remuneração fixa deveria ser o que apresenta menor relação com a performance. A remuneração fixa costuma variar pouco a cada ano e não sofre fortes alterações com a performance da companhia - justamente os componentes que alinham os interesses do executivo e dos acionistas, reduzindo o problema do agente-principal, são os componentes variáveis da remuneração dos executivos, que nesse caso não apresentaram uma relação estatisticamente significante com a performance. Apesar de estatisticamente significante, a relação econômica entre a remuneração fixa e a performance da companhia foi muito baixa, de forma que a cada $\mathrm{R} \$ 1.000 .000,00$ de retorno proporcionado aos acionistas, a diretoria estatutária recebe um acréscimo de $\mathrm{R} \$ 42,50$ em sua remuneração fixa $-\beta=0,0000425$.

A regressão representada pela equação (2) acima testa se a performance das ações no período atual afeta a remuneração dos executivos também no período atual. $\mathrm{O}$ fato é que existe uma heterogeneidade no período do pagamento de bônus das companhias. Em alguns casos, a decisão sobre o pagamento dos bônus dos executivos pode ser feita antes do encerramento do ano fiscal, com base em estimativas do resultado gerado no ano. Em outros casos, o conselho de administração aguarda o encerramento do ano fiscal e a apuração do resultado para estabelecer os bônus pagos aos executivos. 
Em resumo, o valor da remuneração variável divulgado nos formulários de referência das companhias não especifica se o ano de pagamento do bônus é diferente do ano de apuração da performance e avaliação do executivo - ou seja, não especifica se o bônus pago no período $t$ refere-se à performance do período $t$ ou do período $t-1$. De forma a endereçar esse problema, utilizamos a regressão representada pela equação (2) acima, adicionando o componente de performance para o período $t-1$ também, conforme a equação (3) abaixo:

$$
\Delta(\text { Remuneração })_{t}=\alpha+\beta_{1} \Delta(S H \text { wealth })_{t}+\beta_{2} \Delta(S H \text { wealth })_{t-1}
$$

Observamos, nesse caso, que existe uma relação positiva e estatisticamente significante entre a performance em $t-1$ e a remuneração baseada em ações, ao nível de significância de $5 \%$. O coeficiente obtido para o $\beta_{2}$ foi de $0,000182-$ para cada $\mathrm{R} \$ 1.000 .000,00$ proporcionados de retorno para os acionistas, a diretoria estatutária é remunerada com $\mathrm{R} \$ 182,00$ em ações da empresa - o que representa uma relação econômica fraca.

Vale mencionar que a inclusão do lag para a performance da companhia reduz o número de observações (de 658 para 532), de forma que os resultados de $\beta_{1}$ acima diferem dos resultados de $\beta$ obtidos para a equação (2) na subseção anterior.

Os resultados da regressão expressa pela equação (3) acima são apresentados na tabela 2 , presente no anexo 2.

De forma a levar em consideração o número de diretores, estimamos também o coeficiente para a seguinte regressão:

$$
\Delta(\text { Remuneração } M E ́ D I A)_{t}=\alpha+\beta \Delta(\text { SH wealth })_{t}
$$

onde Remuneração Média representa a remuneração de toda a diretoria estatutária, dividido pelo número médio de diretores estatutários para o respectivo ano $t$. Assim como observado para a regressão (2) acima, que levava em conta a remuneração total da diretoria, não observamos uma relação estatisticamente 
significante entre nenhum dos componentes de remuneração e a performance da companhia (medida, nesse caso, como a variação do patrimônio dos acionistas) a um nível de significância de 5\%, ao utilizarmos a remuneração média por diretor.

Estimamos a regressão (4) acima, incluindo o componente de performance para o período $t-1$, conforme a equação (5) abaixo:

$$
\Delta(\text { Remuneração } M E ́ D I A)_{t}=\alpha+\beta_{1} \Delta(S H \text { wealth })_{t}+\beta_{2} \Delta(S H \text { wealth })_{t-1}
$$

Observamos novamente o mesmo resultado obtido ao estimarmos a regressão incluindo a remuneração total da diretoria: uma relação positiva e estatisticamente significante entre a performance em $t-1$ e a remuneração média baseada em ações, ao nível de significância de 5\%.

Os resultados das regressões expressas pelas equações (4) e (5) acima, são apresentados nas tabela 3 e 4, respectivamente, presentes no anexo 2.

\subsection{Controlando as Regressões Pelo Tamanho das Companhias}

As regressões realizadas na seção 7.1 assumiam que a sensibilidade da relação entre a remuneração dos executivos e a performance da companhia era independente do tamanho da companhia (seja qual for a medida utilizada para determinar o tamanho das companhias - valor da firma, valor das ações ou qualquer medida contábil).

Schaefer, S. (1998), argumenta que os coeficientes encontrados nas regressões de Jensen e Murphy (que, assim como feito até o momento no presente estudo, estimavam a relação entre remuneração e performance sem discriminar o tamanho das companhias) eram baixos pois havia um viés em relação aos padrões de remuneração das grandes empresas.

Nessa seção estimamos a relação entre a remuneração dos executivos e a performance das companhias com algumas variáveis de controle para o tamanho da empresa, tais como o Book Value (ou o valor contábil do patrimônio líquido das empresas) e a volatilidade do preço das ações das empresas, medida como o 
desvio padrão anualizado da variação logarítmica diária do preço das ações. Ambas as medidas utilizadas como proxy para o tamanho das empresas foram definidas na seção 4.2 deste estudo.

\subsubsection{Relação entre a remuneração dos executivos e a variação no patrimônio dos acionistas, ponderando pelo Book Value das companhias}

De forma a utilizar o Book Value como proxy para o tamanho da companhia, estimamos os coeficientes $\beta$ para a seguinte regressão:

$$
\begin{array}{r}
\Delta(\text { Remuneração })_{t}=\alpha+\beta_{1} \Delta(\text { SHwealth })_{t}+\beta_{2} \Delta(\text { SHwealth })_{t} \times \log (B V)+ \\
\beta_{3} \log (B V)
\end{array}
$$

onde $B V$ representa o Book Value das empresas.

Ao estimarmos a regressão expressa pela equação (6) acima, obtemos uma relação estatisticamente significante entre remuneração e performance, apenas para remuneração fixa e para a remuneração total, a um nível de significância de 5\%, e somente para o coeficiente $\beta_{3}$, referente ao $\log (\mathrm{BV})$. Os resultados da regressão expressa pela equação (6) acima são apresentados na tabela 5, presente no anexo 2.

Para calcularmos a sensibilidade da relação entre remuneração e performance nesse caso, teremos $\beta^{*}=\beta_{1}+\beta_{2} \times \log (B V)$. Dividimos o $\log (B V)$ em quartis, sendo o primeiro quartil o que contém as empresas com o maior $\log (B V)$ e o quarto quartil, o que apresenta as empresas com o menor $\log (B V)$. A tabela 6 abaixo apresenta os resultados da sensibilidade entre remuneração e performance por quartil, e por tipo de remuneração: 
Tabela 6: Sensibilidade da Relação Entre a Remuneração dos Executivos e a Variação no Patrimônio dos Acionistas, Ponderando Pelo Book Value das Companhias, Para Diferentes Valores de Log (BV)

\begin{tabular}{|c|c|c|c|c|c|c|c|c|}
\hline & \multicolumn{2}{|c|}{$\Delta$ (Remuneração Fixa $) \mathrm{t}$} & \multicolumn{2}{|c|}{$\begin{array}{c}\Delta(\text { Remuneração } \\
\text { Variável) } \mathrm{t}\end{array}$} & \multicolumn{2}{|c|}{$\begin{array}{c}\Delta(\text { Rem. Baseada em } \\
\text { Ações }) t\end{array}$} & \multicolumn{2}{|c|}{$\Delta$ (Remuneração Total) } \\
\hline & $\log (\mathrm{BV})$ & $\beta^{*}$ & $\log (\mathrm{BV})$ & $\beta^{*}$ & $\log (\mathrm{BV})$ & $\beta^{*}$ & $\log (B V)$ & $\beta^{*}$ \\
\hline Primeiro Quartil & 9.89 & 0.000022 & 9.89 & 0.00008 & 9.89 & 0.00008 & 9.89 & 0.0001847 \\
\hline Segundo Quartil & 9.35 & -0.000010 & 9.35 & 0.00010 & 9.35 & 0.00010 & 9.35 & 0.0001936 \\
\hline Terceiro Quartil & 9.04 & -0.000027 & 9.04 & 0.0001122 & 9.04 & 0.00012 & 9.04 & 0.00020 \\
\hline Quarto Quartil & 8.51 & -0.000058 & 8.51 & 0.0001331 & 8.51 & 0.00014 & 8.51 & 0.0002072 \\
\hline
\end{tabular}

Podemos observar que, para o primeiro quartil, com as empresas que apresentam o maior valor de $\log (\mathrm{BV})$, a sensibilidade entre a remuneração fixa e performance é maior que para os demais quartis, obtendo um $\beta^{*}=0,00022$, de forma que a cada $\mathrm{R} \$ 1.000 .000,00$ proporcionados de retorno aos acionistas a diretoria é remunerada com $\mathrm{R} \$ 220,00$. Do segundo quartil em diante, o coeficiente $\beta^{*}$ é inclusive negativo, de forma que quanto maior a performance da companhia, menor seria a remuneração fixa do executivo. Já para remuneração total, temos o efeito contrário, de forma que, para o primeiro quartil (ou para as empresas com o maior Log (BV)), temos uma sensibilidade menor, com $\beta^{*}=$ 0,00018 (a cada $\mathrm{R} \$ 1.000 .000,00$ proporcionados de retorno aos acionistas a diretoria é remunerada com $\mathrm{R} \$ 180,00)$.

\subsubsection{Relação entre a remuneração dos executivos e a variação no patrimônio dos acionistas, ponderando pela volatilidade das companhias}

Com base nos estudos de Clementi e Cooley (2009), estimamos também a seguinte regressão, de forma a controlar a relação entre remuneração e performance, pelo nível de risco das empresas, representado como a variância no preço das ações:

$$
\begin{array}{r}
\Delta(\text { Remuneração })_{t}=\alpha+\beta_{1} \Delta(\text { SHwealth })_{t}+\beta_{2} \Delta(\text { SHwealth })_{t} \times F(\sigma)+ \\
\beta_{3} F(\sigma)
\end{array}
$$


onde, $F(\sigma)$ representa a variância no preço das ações das companhias.

Empresas maiores, em termos de valor da firma ou valor das ações, costumam ser mais líquidas, apresentando um volume de negociações maior que empresas com um valor de mercado menor. Como o volume de negociações costuma ser maior para empresas maiores, seus valores de mercado costumam apresentar maior variação também. Isso implica que o risco assumido pela administração para um dado coeficiente de sensibilidade entre remuneração e performance, tende a ser maior, o quão maior for o tamanho da empresa.

Os resultados da regressão expressa pela equação (7) acima são apresentados na tabela 7, presente no anexo 2. Encontramos uma relação positiva e estatisticamente significante para a relação entre a remuneração fixa e a performance (medida como a variação no patrimônio dos acionistas), mas uma relação negativa e estatisticamente significante tanto para a remuneração fixa e a interação entre performance e a variância do preço das ações $\left(\Delta(\text { SHwealth })_{t} \times\right.$ $F(\sigma)$ ), quanto para a remuneração fixa e a variação do preço das ações apenas todas a um nível de significância de 5\%.

O coeficiente $\beta_{3}$, (a interação com a variância do preço das ações), é também negativo e estatisticamente significante para a relação com a remuneração baseada em ações e para a remuneração total da diretoria estatutária, de forma que, quanto maior a variância no preço das ações, menor tende a ser a remuneração dos executivos

Para calcularmos a sensibilidade da relação entre remuneração e performance nesse caso, teremos $\beta^{*}=\beta_{1}+\beta_{2} \times F(\sigma)$. Dividimos o $F(\sigma) \mathrm{em}$ quartis, sendo o primeiro quartil o que contém as empresas com o maior $F(\sigma)$ e o quarto quartil, o que apresenta as empresas com o menor $F(\sigma)$. A tabela 8, expressa abaixo, apresenta os resultados da sensibilidade entre remuneração e performance por quartil, e por tipo de remuneração: 
Tabela 8: Sensibilidade da Relação Entre a Remuneração dos Executivos e a Variação no Patrimônio dos Acionistas, Ponderando Pela Volatilidade das Companhias, Para Diferentes Valores de F( $\sigma)$

\begin{tabular}{|c|c|c|c|c|c|c|c|c|}
\hline & \multicolumn{2}{|c|}{$\Delta$ (Remuneração Fixa) $t$} & \multicolumn{2}{|c|}{$\begin{array}{c}\Delta(\text { Remuneração } \\
\text { Variável) } \mathrm{t}\end{array}$} & \multicolumn{2}{|c|}{$\begin{array}{c}\Delta(\text { Rem. Baseada em } \\
\text { Ações }) t\end{array}$} & \multicolumn{2}{|c|}{$\Delta$ (Remuneração Total) } \\
\hline & $\mathrm{F}(\sigma)$ & $\beta^{*}$ & $\mathrm{~F}(\sigma)$ & $\beta^{*}$ & $\mathrm{~F}(\sigma)$ & $\beta^{*}$ & $\mathrm{~F}(\sigma)$ & $\beta^{*}$ \\
\hline Primeiro Quartil & 62.80 & -0.000092 & 62.80 & 0.000069 & 62.80 & -0.000041 & 62.80 & -0.000175 \\
\hline Segundo Quartil & 42.73 & -0.000006 & 42.73 & 0.000065 & 42.73 & 0.000015 & 42.73 & 0.000056 \\
\hline Terceiro Quartil & 37.03 & 0.000019 & 37.03 & 0.000064 & 37.03 & 0.000031 & 37.03 & 0.000121 \\
\hline Quarto Quartil & 31.33 & 0.000043 & 31.33 & 0.000063 & 31.33 & 0.000047 & 31.33 & 0.000187 \\
\hline
\end{tabular}

Para a remuneração fixa, onde obtivemos um resultado estatisticamente significante, podemos observar que o coeficiente é negativo para o primeiro quartil e para o segundo quartil, de forma que empresas com maior volatilidade teriam uma relação negativa entre a performance obtida para a companhia e a remuneração fixa dos executivos. Já as empresas do terceiro e quarto quartis, apresentam uma relação positiva entre essas variáveis. Para o quarto quartil, observamos um coeficiente $\beta^{*}=0,000043$ (a cada $\mathrm{R} \$ 1.000 .000,00$ proporcionados de retorno aos acionistas a diretoria é remunerada com $\mathrm{R} \$ 43,00$ ).

\subsection{Relação entre a remuneração dos executivos e a performance contábil das companhias}

A utilização do retorno proporcionado aos acionistas (medido como a variação do Market Cap somado aos dividendos distribuídos) como medida de performance, é apropriada para medir o objetivo do principal no problema do agente-principal envolvendo os executivos (como agente) e os acionistas (como principal). No entanto, não deveria ser a única medida de avaliação de performance na elaboração dos contratos com os executivos. O preço das ações pode variar devido a várias razões que, muitas vezes, independem de quaisquer ações tomadas pelos executivos (seja essa variação positiva, ou negativa).

Bengt Holmstrom (1979) argumenta que um contrato ótimo deveria envolver outras variáveis que não sejam apenas o objetivo do principal. Devido à 
assimetria de informações, informações imperfeitas devem ser utilizadas de forma a reduzir o Risco Moral, como avaliações individuais dos executivos e medidas contábeis de performance, por exemplo.

Segundo o estudo do autor, informações adicionais são de extremo valor porque permitem uma avaliação mais precisa da performance do agente - o que não é possível identificar apenas com a variação no preço das ações.

Nessa subseção, iremos utilizar algumas medidas contábeis como medidas de performance dos executivos para estimar a relação entre remuneração e performance. A sensibilidade da relação entre remuneração e performance, ou os $\beta$ 's, nas regressões abaixo representam a variação na remuneração dos executivos, em Reais, para cada R \$1,00 de variação na medida contábil utilizada.

\subsubsection{Receita Líquida}

Nesta subseção estimamos a relação entre a remuneração dos executivos e a Receita Líquida da companhia no ano corrente. Estimamos os resultados dos $\beta$ 's para a regressão representada pela equação (8), abaixo:

$$
\Delta(\text { Remuneração })_{t}=\alpha+\beta \Delta(\text { Receita Líquida })_{t}
$$

onde, a variável explicada Remuneração é dividida entre (i) Remuneração Fixa, (ii) Remuneração Variável, (iii) Remuneração Baseada em Ações, e (iv) Remuneração Total, que inclui a soma de toda a remuneração da diretoria

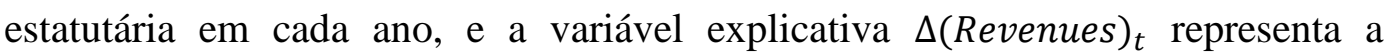
variação na Receita Liquida da companhia, no ano corrente.

Os resultados da regressão expressa pela equação (8) acima são apresentados na tabela 9 , presente no anexo 2 . Podemos observar pelos resultados que não existe uma relação estatisticamente significante entre nenhum dos componentes de remuneração e a performance da companhia (medida, nesse caso, como a variação da Receita Líquida da companhia no ano corrente) a um nível de significância de $5 \%$. 
De forma a levar em consideração o número de diretores, estimamos também o coeficiente para a seguinte regressão:

$$
\Delta(\text { Remuneração MÉDIA })_{t}=\alpha+\beta \Delta(\text { Receita Líquida })_{t}
$$

onde Remuneração MÉDIA representa a remuneração de toda a diretoria estatutária, dividido pelo número médio de diretores estatutários para o respectivo ano t. Assim como observado para a remuneração total da diretoria, não observamos uma relação estatisticamente significante entre nenhum dos componentes de remuneração e a performance da companhia (medida, nesse caso, como a variação da Receita Líquida da companhia) a um nível de significância de 5\% ao utilizarmos a remuneração média da diretoria como variável explicada. Os resultados da regressão representada pela equação (9) acima são expostos na tabela 10, presente no anexo 2 .

É razoável que a Receita Líquida não seja a melhor medida de performance para atrelar a remuneração dos executivos. As empresas podem apresentar crescimento na Receita mas perda na rentabilidade, o que iria contra o interesse dos acionistas (salvo alguns casos específicos). Dessa forma, métricas como EBITDA (Earnings Before Interest, Taxes, Depreciation and Amortization) ou o Lucro Líquido são métricas mais adequadas para se medir a performance da companhia e, consequentemente, dos executivos. Nas subseções abaixo regredimos as diferentes formas de remuneração contra essas medidas de performance contábeis.

\subsubsection{EBITDA (Earnings Before Interest, Taxes, Depreciation and Amortization)}

O EBITDA representa o Lucro Líquido antes de contabilizar o resultado financeiro, os impostos sobre o lucro, depreciação e amortização. É uma medida comumente utilizada para medir os resultados operacionais das empresas, já que considera apenas os custos e despesas necessárias para a manutenção das operações diárias, ou do core business da empresa. É uma forma de medir os 
lucros sem ter que considerar outros fatores como os custos de financiamento, regimes tributários ou práticas contábeis (que afetam a depreciação e amortização).

Nesta subseção estimamos a relação entre a remuneração dos executivos e o EBITDA da companhia no ano corrente. Estimamos os $\beta$ 's para a regressão representada pela equação (10), abaixo:

$$
\Delta(\text { Remuneração })_{t}=\alpha+\beta \Delta(E B I T D A)_{t}
$$

onde, a variável explicada Remuneração é dividida entre os diversos componentes da remuneração anual da diretoria (Remuneração Fixa, Remuneração Variável, Remuneração Baseada em Ações, e Remuneração Total), e a variável explicativa $\Delta(E B I T D A)_{t}$ representa a variação do EBITDA da companhia, no ano corrente.

Os resultados da regressão expressa pela equação (10) acima são apresentados na tabela 11, presente no anexo 2. Podemos observar pelos resultados que, ao utilizarmos o EBITDA como medida de performance, obtemos uma relação positiva e estatisticamente significante entre a remuneração baseada em ações e a variação do EBITDA, a um nível de significância de 5\%. O $\beta$ encontrado para essa relação foi de 0,000298, de forma que, a cada $R \$$ 1.000.000,00 de acréscimo no EBITDA da companhia, o executivo é remunerado com $\mathrm{R} \$ 298,00$ em ações da companhia.

De forma a levar em consideração o número de diretores, estimamos também o coeficiente para a seguinte regressão:

$$
\Delta(\text { Remuneração } M E ́ D I A)_{t}=\alpha+\beta \Delta(E B I T D A)_{t}
$$

onde Remuneração MÉDIA representa a remuneração de toda a diretoria estatutária, dividido pelo número médio de diretores estatutários para o respectivo ano $t$. Assim como observado para a regressão (10) acima, que levava em conta a remuneração total da diretoria, observamos uma relação positiva e estatisticamente significante apenas entre a remuneração baseada em ações e a 
variação do EBITDA, a um nível de significância de 5\%, ao utilizarmos a remuneração média por diretor. Os resultados da regressão representada pela equação (11) acima são expostos na tabela 12, presente no anexo 2.

\subsubsection{Lucro Líquido}

Enquanto o EBITDA leva em consideração apenas o resultado operacional da companhia, o Lucro Líquido leva em consideração também o resultado financeiro, despesas com depreciação e amortização (que não representam dispêndios de caixa) e impostos sobre o lucro. Costuma ser uma medida menos adequada para comparar operações de empresas diferentes dado que as empresas podem apresentar estruturas de capital e regimes tributários diferentes.

Nesta subseção estimamos a relação entre a remuneração dos executivos e o Lucro Líquido da companhia no ano corrente. Estimamos os $\beta$ 's para a regressão representada pela equação (12), abaixo:

$$
\Delta(\text { Remuneração })_{t}=\alpha+\beta \Delta(\text { Lucro Líquido })_{t}
$$

onde, a variável explicada Remuneração é dividida entre os diversos componentes da remuneração anual da diretoria (Remuneração Fixa, Remuneração Variável, Remuneração Baseada em Ações, e Remuneração Total), e a variável explicativa $\Delta(\text { Lucro Líquido })_{t}$ representa a variação do Lucro Líquido da companhia, no ano corrente.

Os resultados da regressão expressa pela equação (12) acima são apresentados na tabela 13, presente no anexo 2. Podemos observar pelos resultados que, ao utilizarmos o Lucro Líquido como medida de performance, obtemos uma relação positiva e estatisticamente significante entre a remuneração baseada em ações e a variação do Líquido, e também entre a remuneração total e a variação do Lucro Líquido, a um nível de significância de 5\%. Para a remuneração baseada em ações encontramos um $\beta$ de 0,000575 , o que significa que para cada $\mathrm{R} \$ 1.000 .000,00$ de acréscimo no Lucro Líquido anual, a diretoria 
estatutária recebe um acréscimo de $\mathrm{R}$ \$ 575,00 em sua remuneração baseada em ações da companhia. Já para a remuneração total, encontramos um $\beta$ igual a 0,000483, de forma que, para cada $\mathrm{R} \$ 1.000 .000,00$ de acréscimo no Lucro Líquido anual, a diretoria estatutária recebe um acréscimo de $\mathrm{R} \$ 483,00$ na remuneração total anual.

De forma a levar em consideração o número de diretores, estimamos também o coeficiente para a seguinte regressão:

$$
\Delta(\text { Remuneração } M E ́ D I A)_{t}=\alpha+\beta \Delta(\text { Lucro Líquido })_{t}
$$

onde Remuneração MÉDIA representa a remuneração de toda a diretoria estatutária, dividido pelo número médio de diretores estatutários para o respectivo ano $t$. Assim como observado para a regressão (12) acima, que levava em conta a remuneração total da diretoria, observamos uma relação estatisticamente significante tanto para a remuneração baseada em ações, quanto para a remuneração total, e a performance da companhia (medida, nesse caso, como a variação do Lucro Líquido da companhia) a um nível de significância de 5\%. Os resultados da regressão representada pela equação (13) acima são expostos na tabela 14, presente no anexo 2. 


\section{Conclusões}

O objetivo desse estudo é analisar a relação entre a remuneração dos diretores estatutários nas empresas listadas no Novo Mercado e a performance dessas companhias. A literatura acadêmica no Brasil ainda é muito incipiente nesse tema, de forma que não existem tantos estudos expressivos sobre o tema, quando comparado com a literatura internacional. Um dos motivos para isso é o fato de que a divulgação da remuneração da diretoria estatutária é uma exigência recente da CVM, o que faz com que a base de dados de remuneração de executivos ainda seja muito pequena no Brasil - a título de comparação, as regressões realizadas nesse estudo apresentaram entre 521 e 709 observações, ao passo que as regressões no estudo de Murphy e Jensen (1990), o mais antigo aqui abordado, apresentavam entre 7.688 e 7.750 observações.

Ao analisar a relação entre remuneração dos executivos e a performance das companhias, deveríamos observar uma relação positiva e estatisticamente (e economicamente) significante entre as duas variáveis, caso a elaboração dos contratos de remuneração dos executivos endereçassem os problemas mencionados na teoria do Agente-Principal. O que observamos no presente estudo, é que ao utilizar a variação no patrimônio dos acionistas como medida de performance, observamos uma relação positiva e estatisticamente significante apenas para a remuneração baseada em ações e a performance com lag, (conforme observado na seção 7.1). No entanto, nesses casos, o coeficiente $\beta$ encontrado foi de 0,000182 e 0,0000363, utilizando a remuneração total da diretoria e a remuneração média da diretoria, respectivamente, o que representa uma relevância econômica muito baixa.

Já ao utilizar métricas contábeis como medida de performance, percebemos um resultado um pouco mais significativo estatisticamente e economicamente: observamos resultados positivos e estatisticamente significantes para a relação entre a remuneração baseada em ações e a variação do EBITDA, tanto ao utilizarmos a remuneração total da diretoria estatutária, quanto quando 
utilizamos a remuneração média, observando coeficientes de 0,000298 e 0,0000724, respectivamente. Ao utilizarmos o lucro líquido como medida de performance, observamos uma relação positiva e estatisticamente significante tanto para a relação entre a remuneração baseada em ações e a variação do lucro líquido, quanto para a remuneração total e a variação no lucro líquido. Para o primeiro caso, os coeficientes encontrados foram 0,000575 e 0,000119, para a remuneração total da diretoria estatutária e para a remuneração média da diretoria estatutária, respectivamente; para o segundo caso, os coeficientes encontrados foram 0,000483 e 0,0000916, para a remuneração total da diretoria estatutária e para a remuneração média da diretoria estatutária, respectivamente.

Apesar de alguns resultados serem estatisticamente significantes, a relevância econômica é sempre muito baixa em todos os resultados encontrados. Como exemplo, para o coeficiente mais alto mencionado acima, a diretoria estatutária recebe $\mathrm{R} \$ 575,00$ para cada $\mathrm{R} \$ 1.000 .000,00$ proporcionados de retorno aos acionistas (este medido como a variação do lucro líquido da companhia). Mesmo ao controlarmos as regressões pelo tamanho das empresas (utilizando o Book Value ou o risco, medido pela volatilidade das ações como variáveis de controle), de forma a tratar a heterogeneidade da amostra de empresas, os resultados não foram muito diferentes, conforme exposto na seção 7.2 .

A baixa relação econômica entre remuneração e performance parece inconsistente com o problema do agente-principal. Um dos motivos que poderia explicar o resultado encontrado é o fato de que existem muitas forças políticas, públicas e privadas, que afetam a remuneração dos executivos. As empresas podem sofrer pressão dos acionistas para que os executivos não recebam remunerações exorbitantes. Discussões nas reuniões do conselho ou até mesmo brigas políticas internas na administração das empresas podem levar a uma distorção na remuneração dos executivos.

Outro motivo, seria o fato de que, conforme elencado por Holmstrom (1979), os contratos com os executivos devem conter informações imperfeitas para que sejam mais eficientes. A performance da companhia pode ser positiva por motivos exógenos à administração, assim como pode ser negativa por razões 
que independem da administração da companhia. Existem outras formas de avaliação, por vezes mais subjetivas, que não seja só a performance da companhia.

Em comparação aos resultados internacionais citados na seção 2, a definição de remuneração utilizada no presente estudo se aproxima mais da definição utilizada por Murphy e Jensen, no sentido de que não leva em consideração a variação no valor das ações e stock options detidas pelos executivos como forma de remuneração. Da mesma forma, nossos resultados foram mais próximos dos resultados encontrados por esses autores, dado que encontramos relações positivas e estatisticamente significantes entre remuneração e performance, porém com coeficientes muito baixos, representando pouco significado econômico no que concerne o problema do Agente-Principal. Vale ressaltar também que a maior parte dos estudos internacionais é baseado na remuneração do $\mathrm{CEO}$, ao passo que o presente estudo foi feito com base na remuneração da diretoria estatutária como um todo. Enquanto nos EUA os executivos são obrigados a divulgar seus salários individualmente, no Brasil as empresas são obrigadas apenas a divulgar a remuneração global da diretoria estatutária - o que passou a ser uma obrigação a partir de 2009, por exigência da CVM (através da instrução iCVM 480).

Motivações para futuros estudos sobre o tema no mercado brasileiro deveriam incluir medidas mais amplas de remuneração dos executivos, levando em conta a variação no valor das ações sob posse dos mesmos. Para o mercado brasileiro, as informações de remuneração dos executivos e o percentual de ações detidas pelos mesmos ainda são muito dispersas, o que dificulta a realização de pesquisas mais profundas nesse sentido.

Outro ponto não abordado no presente estudo, mas de extrema relevância, são os efeitos da remuneração dos executivos na performance da companhia nos anos subsequentes. Mesmo para o mercado americano, com bases de dados mais longas e detalhadas sobre a remuneração de executivos, esse é um tema que ainda foi pouco documentado. Um aumento na remuneração leva os executivos a trabalhar mais em benefício dos acionistas? Esses são alguns dos temas que podem ser mais explorados no mercado brasileiro. 


\section{Referências bibliográficas}

Aggarwal, Rajesh e Andrew Samwich (1998): "The Other Side of the Tradeoff: The Impact of Risk on Executive Compensation"

Bebchuk, Lucian e Jesse M. Fried (2003): "Executive Compensation as an Agency Problem"

Clementi L., Gian e Thomas F. Cooley (2009): "Executive Compensation: Facts"

Crystal, Graef (1970): "Executive Compensation"

Hall J., Brian e Jeffrey B. Liebman (1997): “Are CEO’s Really Paid Like

Bureaucrats?"

Hart, Oliver e Bengt Holmstrom (1986): "The Theory of Contracts"

Holmstrom, Bengt (1979): "Moral Hazard and Observability"

Jensen C., Michael e Kevin J. Murphy (1990): “CEO Incentives: It's Not How Much You Pay, But How"

Jensen C., Michael e Kevin J. Murphy (1990): "Performance Pay and TopManagement Incentives"

Murphy J., Kevin (1999): “Executive Compensation”

PwC e FGV EAESP (2015): "Remuneração Executiva e Geração de Valor Práticas de Remuneração e Desempenho em Empresas de Capital Aberto no Brasil"

Schaefer, S. (1998): “The Dependence of Pay-Performance Sensitivity on the Size of the Firm" 


\section{Anexo 1}

\section{Figura 1}

\section{Remuneração Média por Diretor}

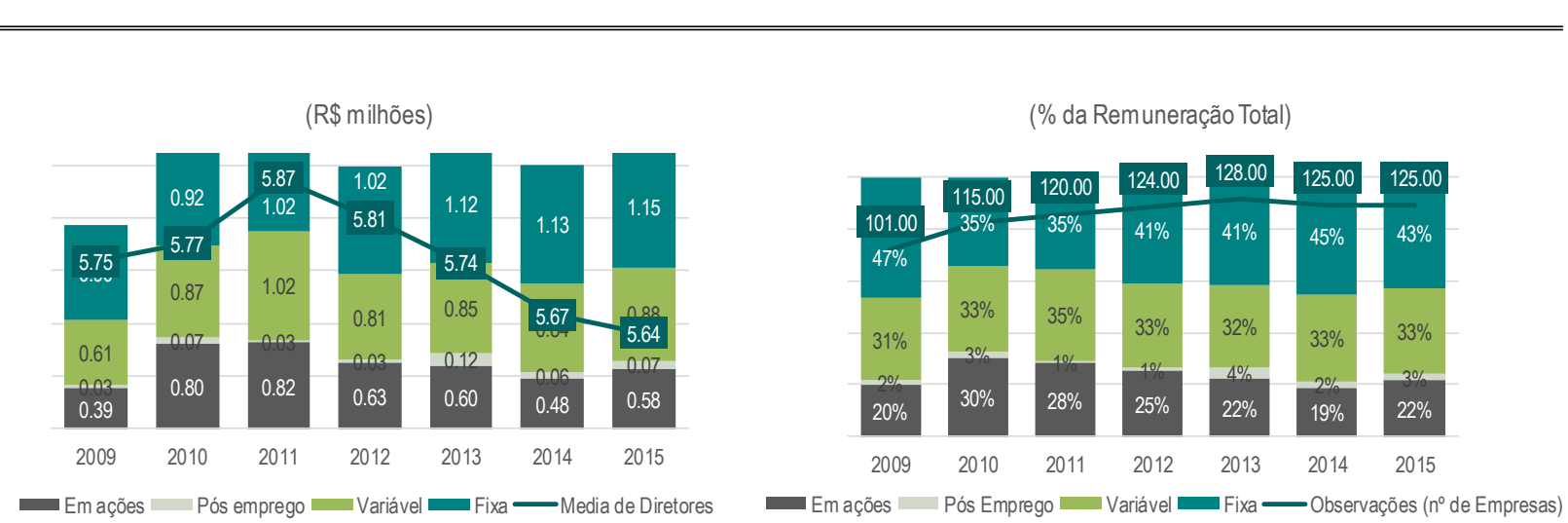

Fonte: CVM (Comissão de Valores Mobiliários) - Formulários de Referência 


\section{Figura 2}

Remuneração Média por Diretor - Empresas do Primeiro Quartil

(R\$ milhões)

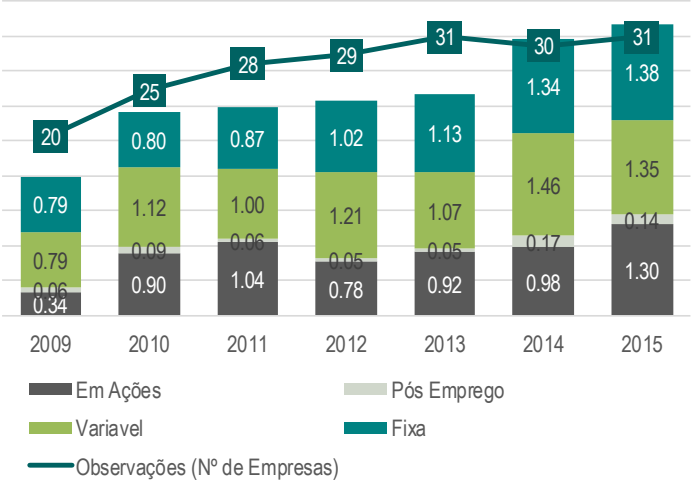

(\% da Remuneração Total)

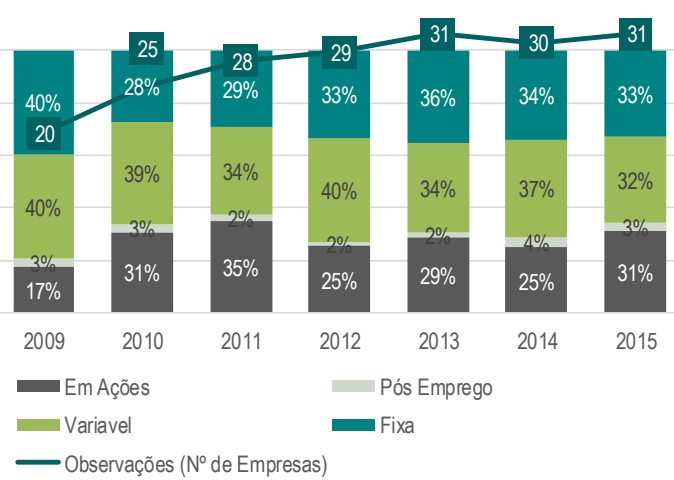

Fonte: CVM (Comissão de Valores Mobiliários) - Formulários de Referência

Remuneração Média por Diretor - Empresas do Último Quartil

(R\$ milhões)

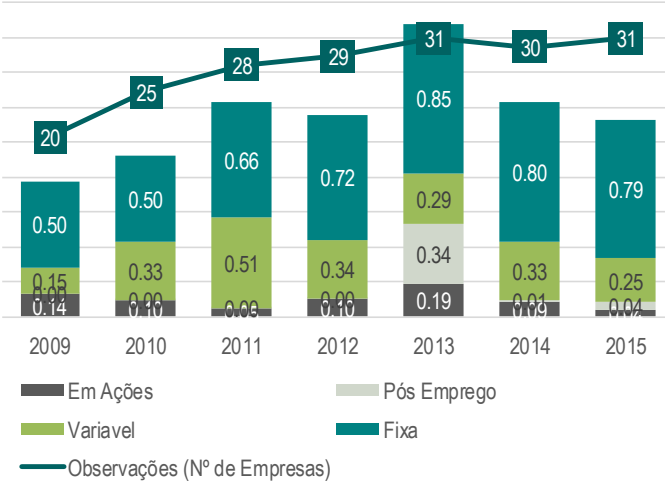

(\% da Remuneração Total)

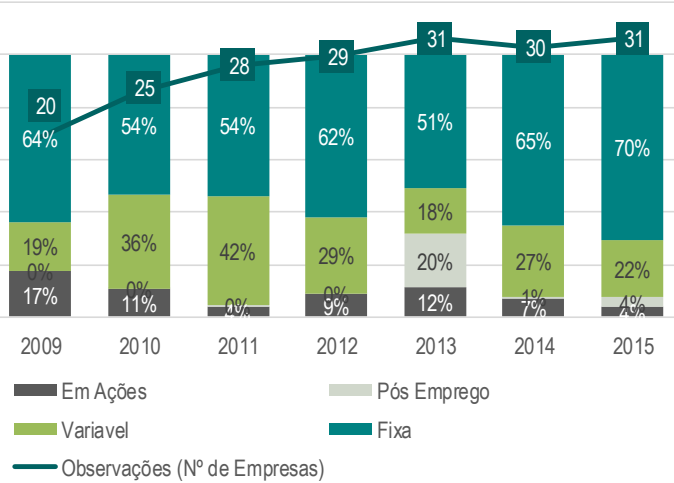

Fonte: CVM (Comissão de Valores Mobiliários) - Formulários de Referência 


\section{Figura 3}

Remuneração Média por Diretor por Setor de Atuação

\section{Financeiro}

(R\$ milhões)

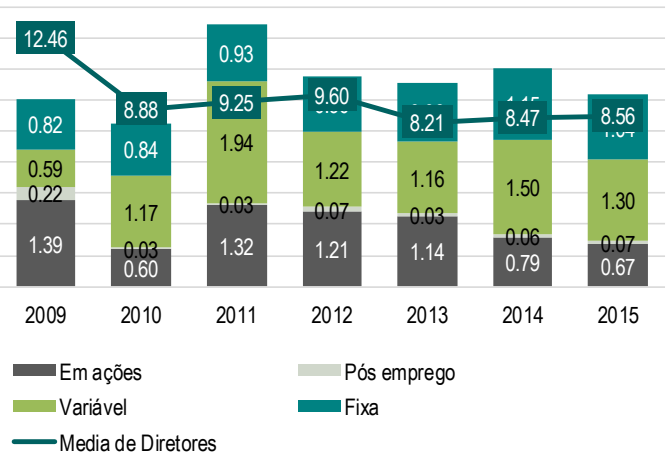

(\% da Remuneração Total)

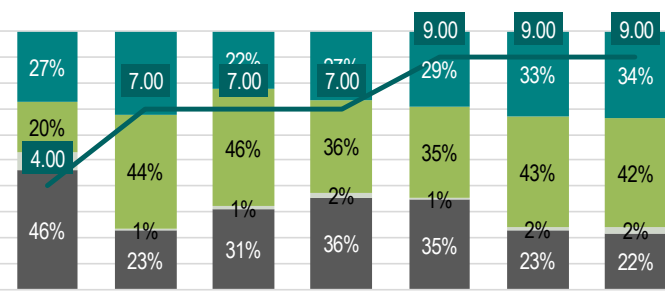

$2009 \quad 2010 \quad 2011 \quad 2012$

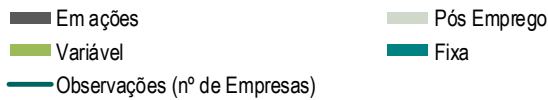

Fonte: CVM (Comissão de Valores Mobiliários) - Formulários de Referência

Educação

( $\mathrm{R}$ milhões)

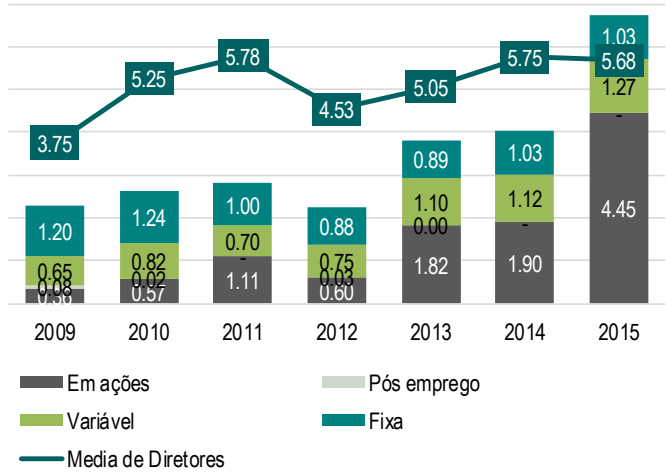

(\% da Remuneração Total)

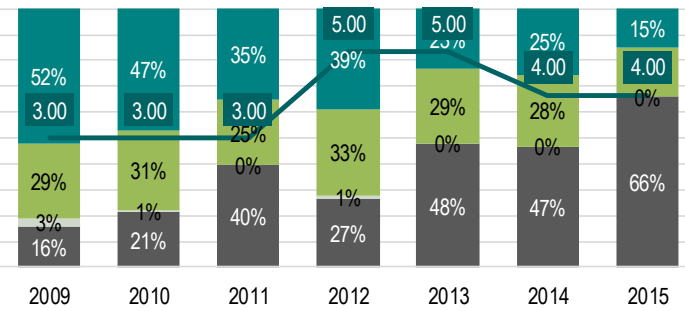

Emações

Variável

Pós Emprego

—Observações ( $n^{\circ}$ de Empresas)

Fonte: CVM (Comissão de Valores Mobiliários) - Formulários de Referência 
$\underline{\text { Imobiliário }}$

( $R$ \$ milhões)

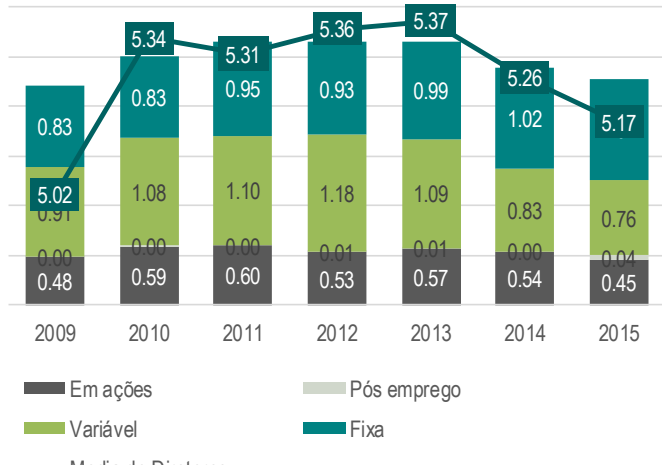

(\% da Remuneração Total)

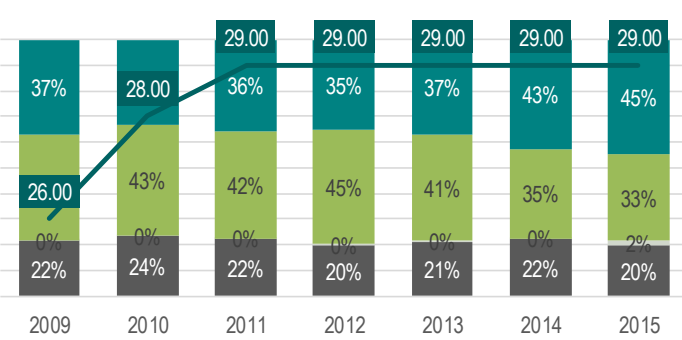

Emações

Pós Emprego

Variável

—Observações ( $n^{0}$ de Empresas)

Fonte: CVM (Comissão de Valores Mobiliários) - Formulários de Referência

\section{Consumo Cíclico}

( $\mathrm{R}$ \$ milhões)
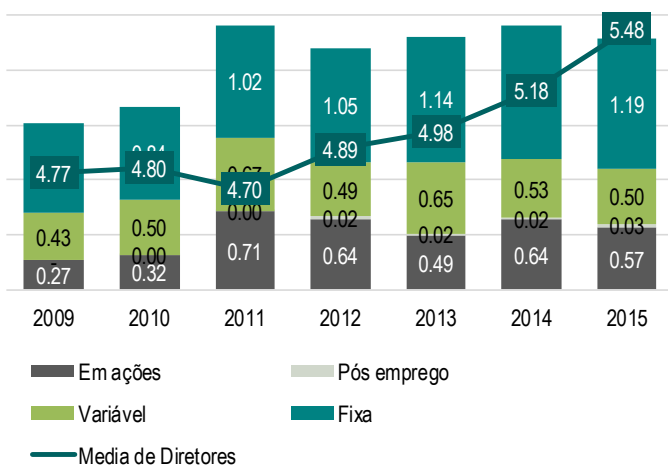

(\% da Remuneração Total)

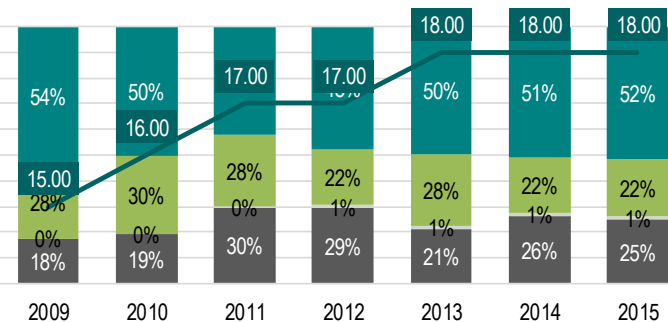

Emações

Varível

Pós Emprego

—observações ( $n^{0}$ de Empresas)

Fonte: CVM (Comissão de Valores Mobiliários) - Formulários de Referência

\section{Consumo Não Cíclico}

(R\$ milhões)

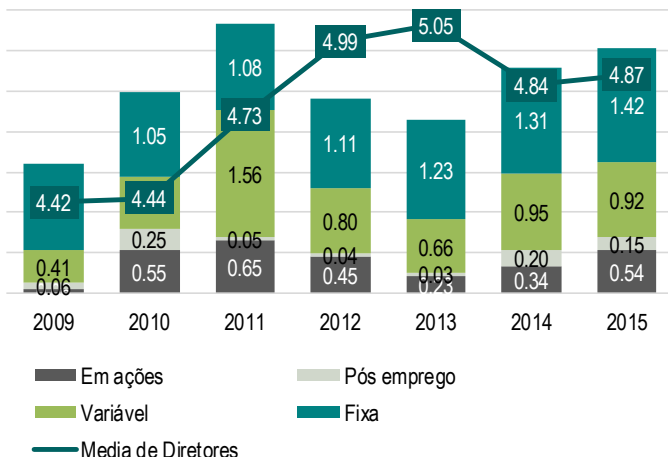

(\% da Remuneração Total)

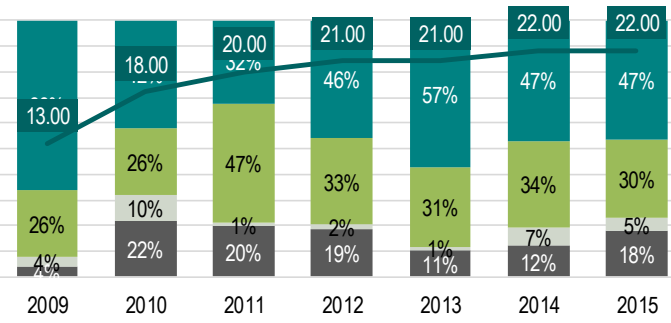

Emações

Variável

Pós Emprego

- Fixa

-Observações ( $n^{0}$ de Empresas)

Fonte: CVM (Comissão de Valores Mobiliários) - Formulários de Referência 
Utilidade Pública

(R\$ milhões)

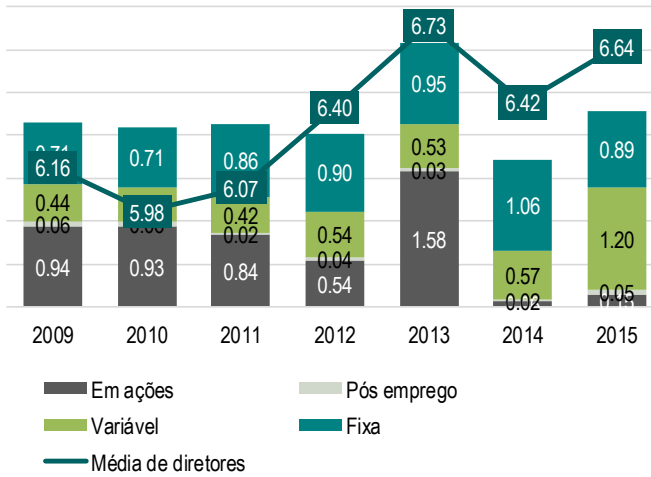

(\% da Remuneração Total)

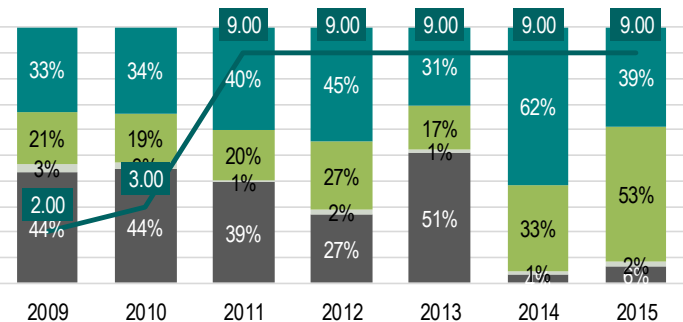

Em ações

Varível

Pós Emprego

Fixa

Fonte: CVM (Comissão de Valores Mobiliários) - Formulários de Referência

\section{Transporte}

(R\$ milhões)

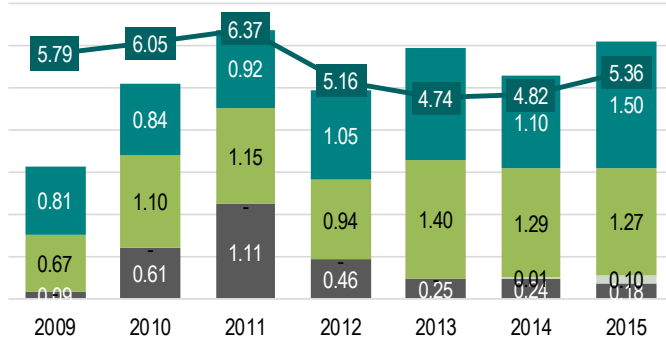

$\begin{array}{ll}\text { Emações } & \text { Pós Emprego } \\ \text { Varível } & \text { Fixa } \\ \text { Média de Diretores } & \end{array}$
(\% da Remuneração Total)

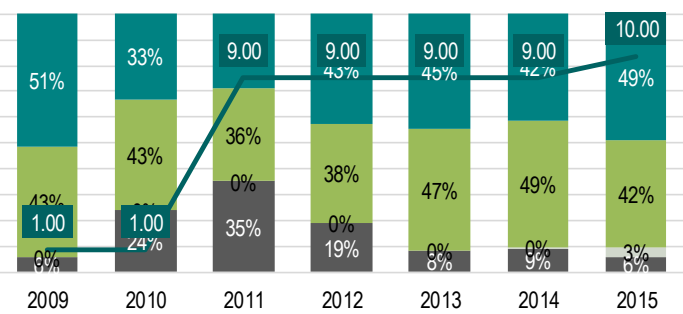

Emações

Variável

Pós Emprego

Fixa

—observações ( $\mathrm{n}^{\circ}$ de Empresas)

Fonte: CVM (Comissão de Valores Mobiliários) - Formulários de Referência

$\underline{\text { Outros }}$

( $\mathrm{R}$ \$ milhões)

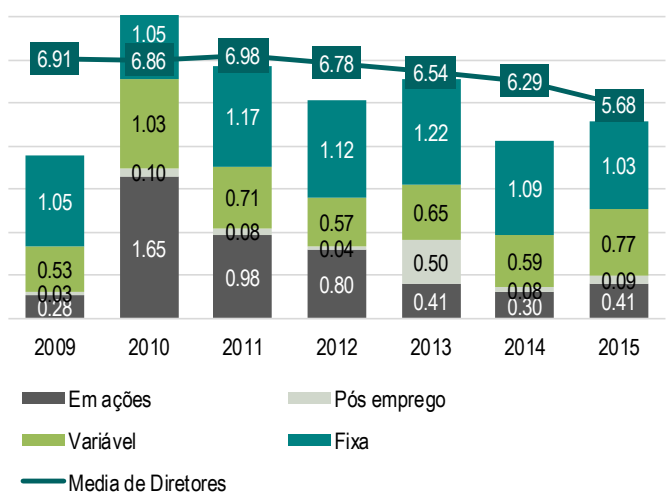

(\% da Remuneração Total)

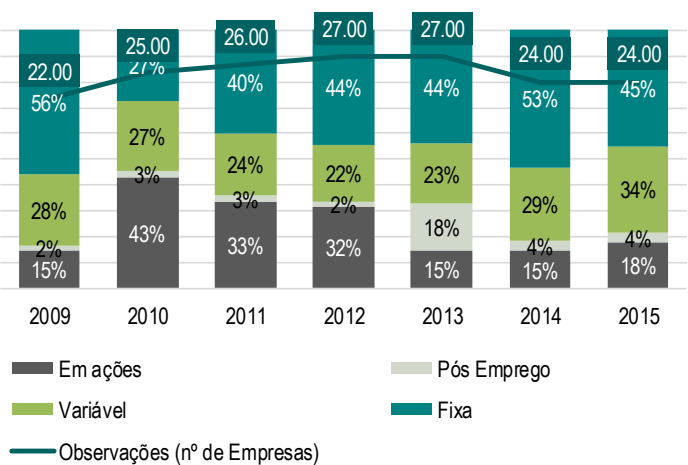

Fonte: CVM (Comissão de Valores Mobiliários) - Formulários de Referência 


\section{Anexo 2}

Tabela 1: Relação Entre a Remuneração dos Executivos e a Variação no Patrimônio dos Acionistas

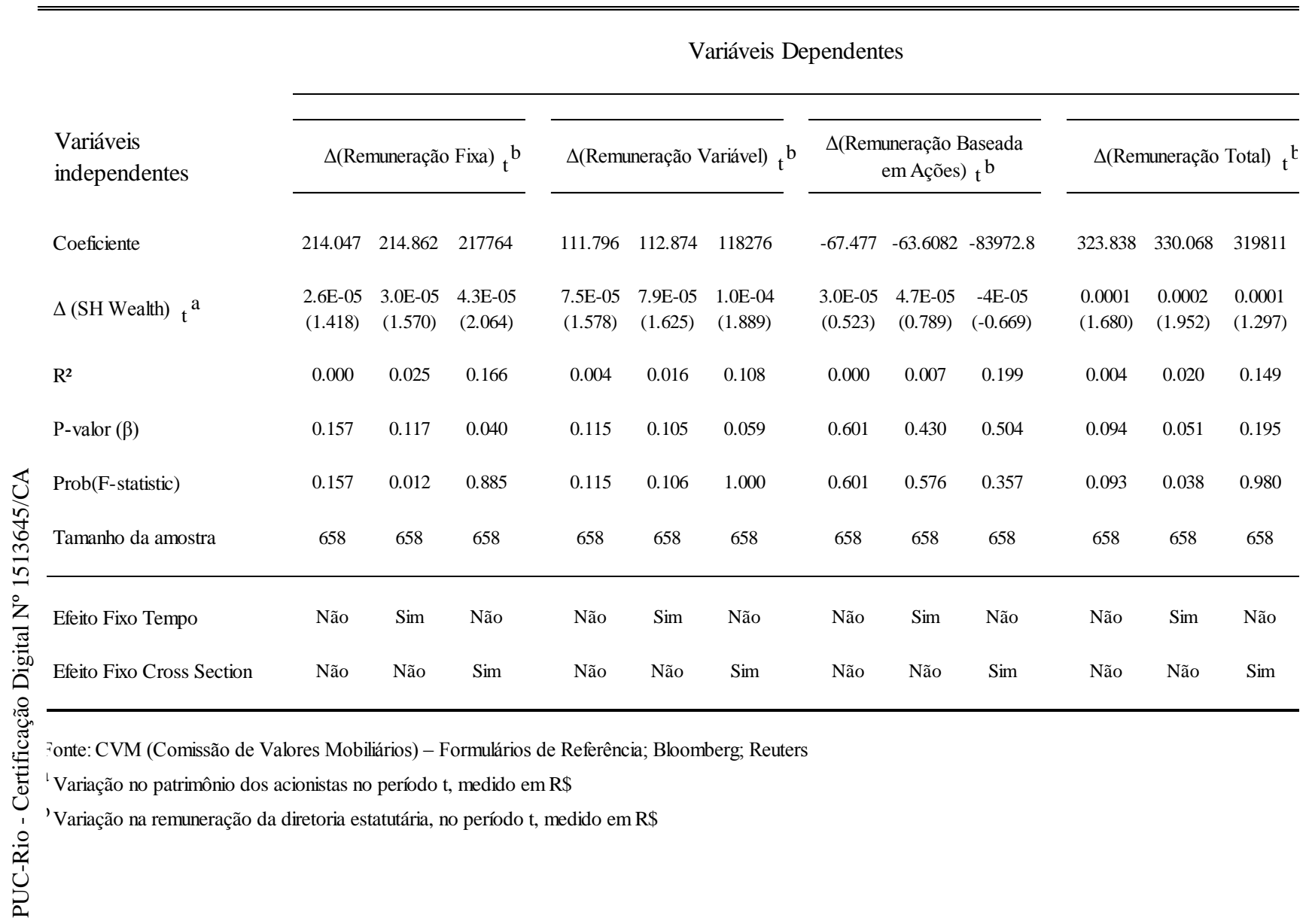


Tabela 2: Relação Entre a Remuneração dos Executivos e a Variação no Patrimônio dos Acionistas com Lag no Período da Performance

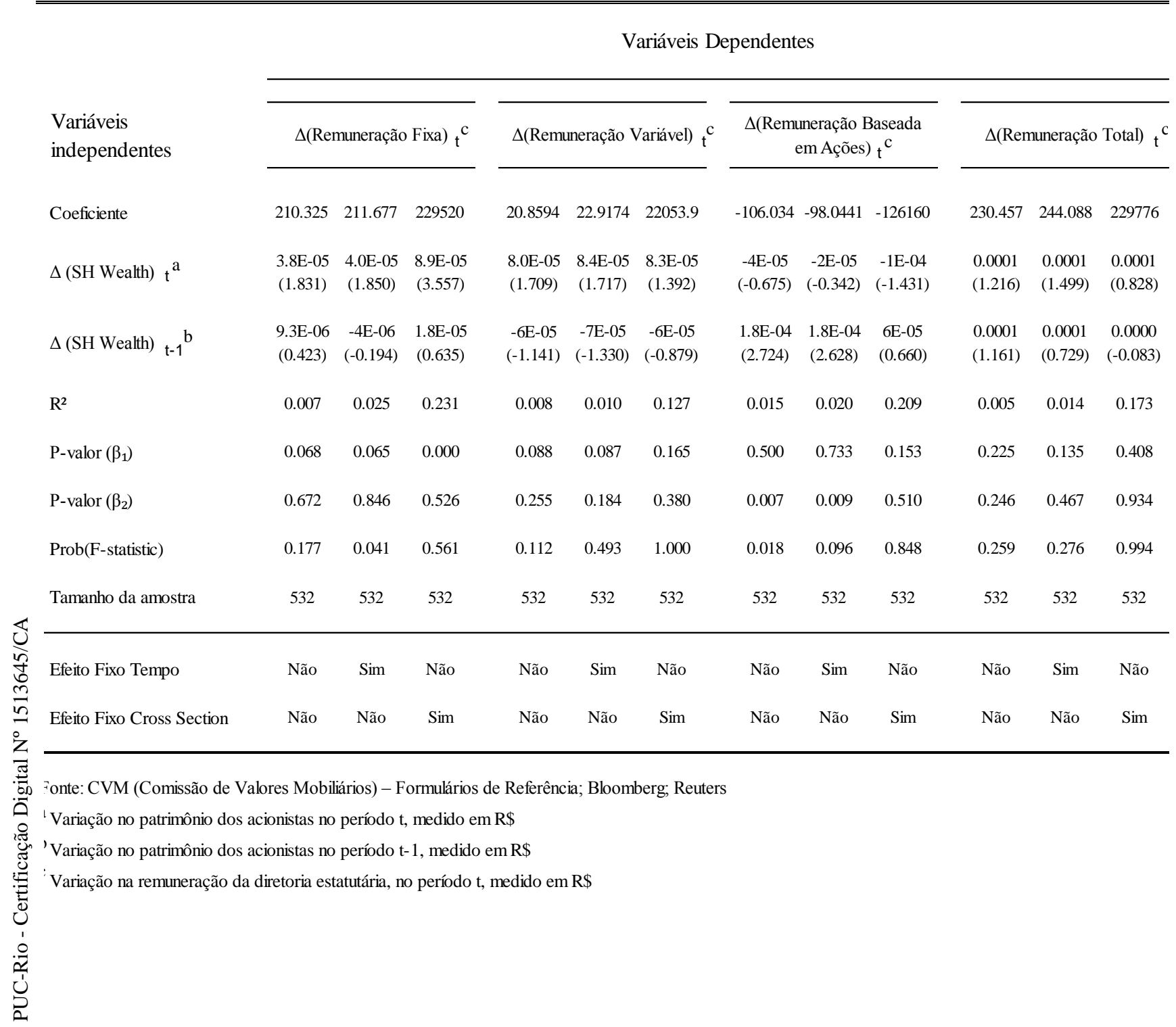


Tabela 3: Relação Entre a Remuneração Média dos Executivos e a Variação no Patrimônio dos Acionistas

\begin{tabular}{|c|c|c|c|c|c|c|c|c|c|c|c|c|}
\hline \multirow{3}{*}{$\begin{array}{l}\text { Variáveis } \\
\text { independentes } \\
\text { Coeficiente }\end{array}$} & \multicolumn{12}{|c|}{ Variáveis Dependentes } \\
\hline & \multicolumn{3}{|c|}{$\begin{array}{c}\Delta \text { (Remuneração Fixa } \\
\text { Média) } \mathrm{t}^{\mathrm{b}}\end{array}$} & \multicolumn{3}{|c|}{$\begin{array}{c}\Delta \text { (Remuneração Variável } \\
\text { Média) } \mathrm{t}^{\mathrm{b}}\end{array}$} & \multicolumn{3}{|c|}{$\begin{array}{l}\Delta \text { (Remuneração Média } \\
\text { Baseada em Ações) } \mathrm{t}^{\mathrm{b}}\end{array}$} & \multicolumn{3}{|c|}{$\begin{array}{c}\Delta \text { (Remuneração Total } \\
\text { Média }) \mathrm{t}^{\mathrm{b}}\end{array}$} \\
\hline & 34.804 & 35.0453 & 35241.1 & -0.24411 & 0.76981 & 723.695 & -28.1728 & -27.157 & -31672.5 & 20.0852 & 22.4744 & 18910.6 \\
\hline$\Delta$ (SH Wealth) $\mathrm{t}^{\mathrm{a}}$ & $\begin{array}{c}4.3 \mathrm{E}-06 \\
(1.319)\end{array}$ & $\begin{array}{c}5.3 \mathrm{E}-06 \\
(1.605)\end{array}$ & $\begin{array}{c}6.1 \mathrm{E}-06 \\
(1.608)\end{array}$ & $\begin{array}{l}1.4 \mathrm{E}-05 \\
(1.225)\end{array}$ & $\begin{array}{l}1.9 \mathrm{E}-05 \\
(1.563)\end{array}$ & $\begin{array}{l}1.8 \mathrm{E}-05 \\
(1.397)\end{array}$ & $\begin{array}{c}3.1 \mathrm{E}-06 \\
(0.253)\end{array}$ & $\begin{array}{l}7.6 \mathrm{E}-06 \\
(0.595)\end{array}$ & $\begin{array}{c}-1 \mathrm{E}-05 \\
(-0.895)\end{array}$ & $\begin{array}{c}2.3 \mathrm{E}-05 \\
(1.271)\end{array}$ & $\begin{array}{c}3.4 \mathrm{E}-05 \\
(1.790)\end{array}$ & $\begin{array}{c}1.8 \mathrm{E}-05 \\
(0.862)\end{array}$ \\
\hline $\mathrm{R}^{2}$ & 0.003 & 0.027 & 0.101 & 0.002 & 0.013 & 0.124 & 0.000 & 0.007 & 0.171 & 0.002 & 0.019 & 0.121 \\
\hline P-valor $(\beta)$ & 0.188 & 0.109 & 0.108 & 0.221 & 0.119 & 0.163 & 0.801 & 0.552 & 0.371 & 0.204 & 0.074 & 0.389 \\
\hline Prob(F-statistic) & 0.188 & 0.007 & 1.000 & 0.221 & 0.213 & 1.000 & 0.800 & 0.610 & 0.832 & 0.204 & 0.051 & 1.000 \\
\hline Tamanho da amostra & 658 & 658 & 658 & 658 & 658 & 658 & 658 & 658 & 658 & 658 & 658 & 658 \\
\hline Efeito Fixo Tempo & Não & Sim & Não & Não & Sim & Não & Não & Sim & Não & Não & Sim & Não \\
\hline Efeito Fixo Cross Section & Não & Não & Sim & Não & Não & Sim & Não & Não & Sim & Não & Não & Sim \\
\hline
\end{tabular}

Fonte: CVM (Comissão de Valores Mobiliários) - Formulários de Referência; Bloomberg; Reuters

'Variação no patrimônio dos acionistas no período t, medido em R\$

'Variação na remuneração média por diretor da diretoria estatutária, no período t, medido em R\$ 
Tabela 4: Relação Entre a Remuneração Média dos Executivos e a Variação no Patrimônio dos Acionistas com Lag no Período da Performance

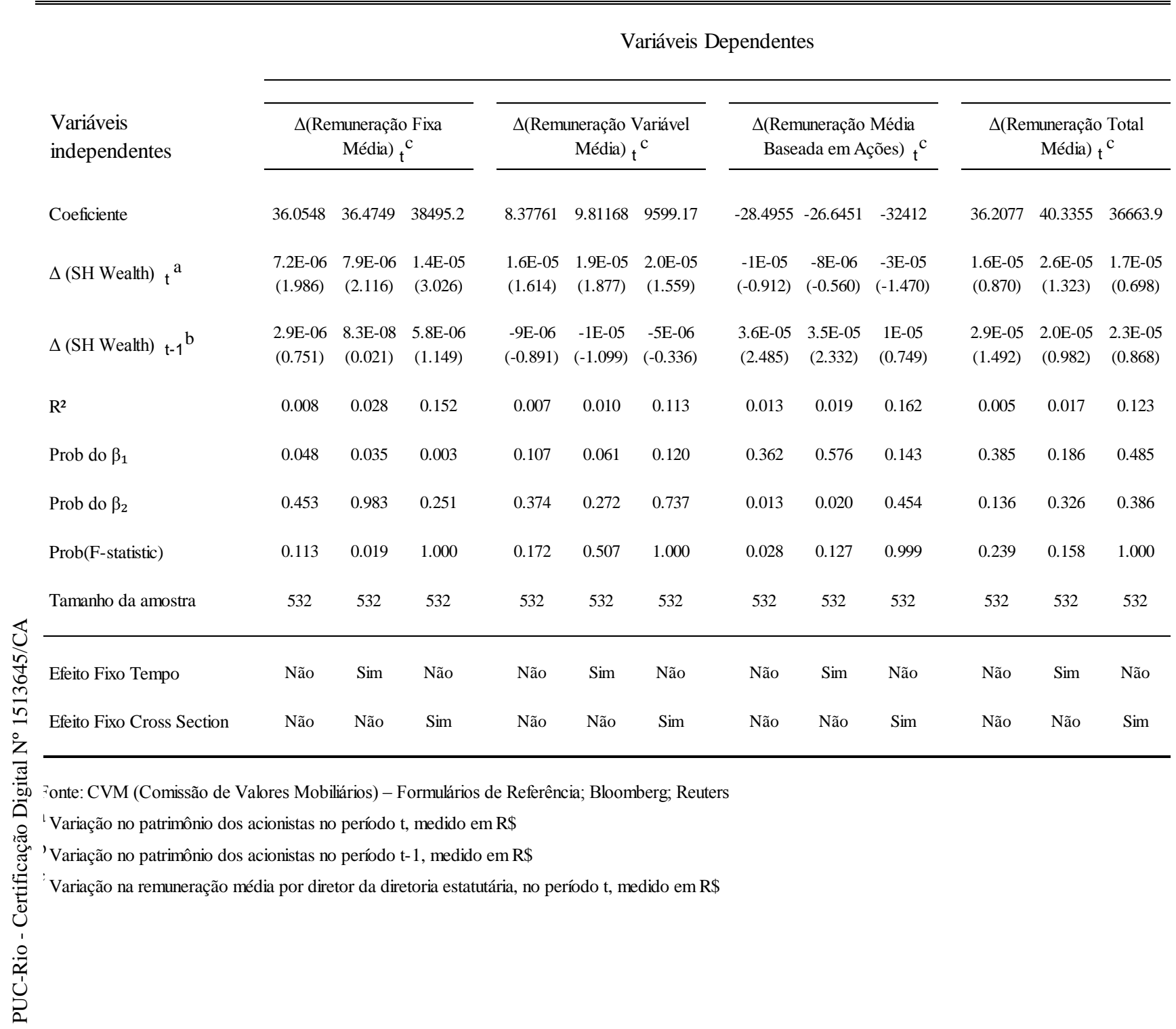


Tabela 5: Relação Entre a Remuneração Média dos Executivos e a Variação no Patrimônio dos Acionistas, Ponderando pelo Book Value das Companhias

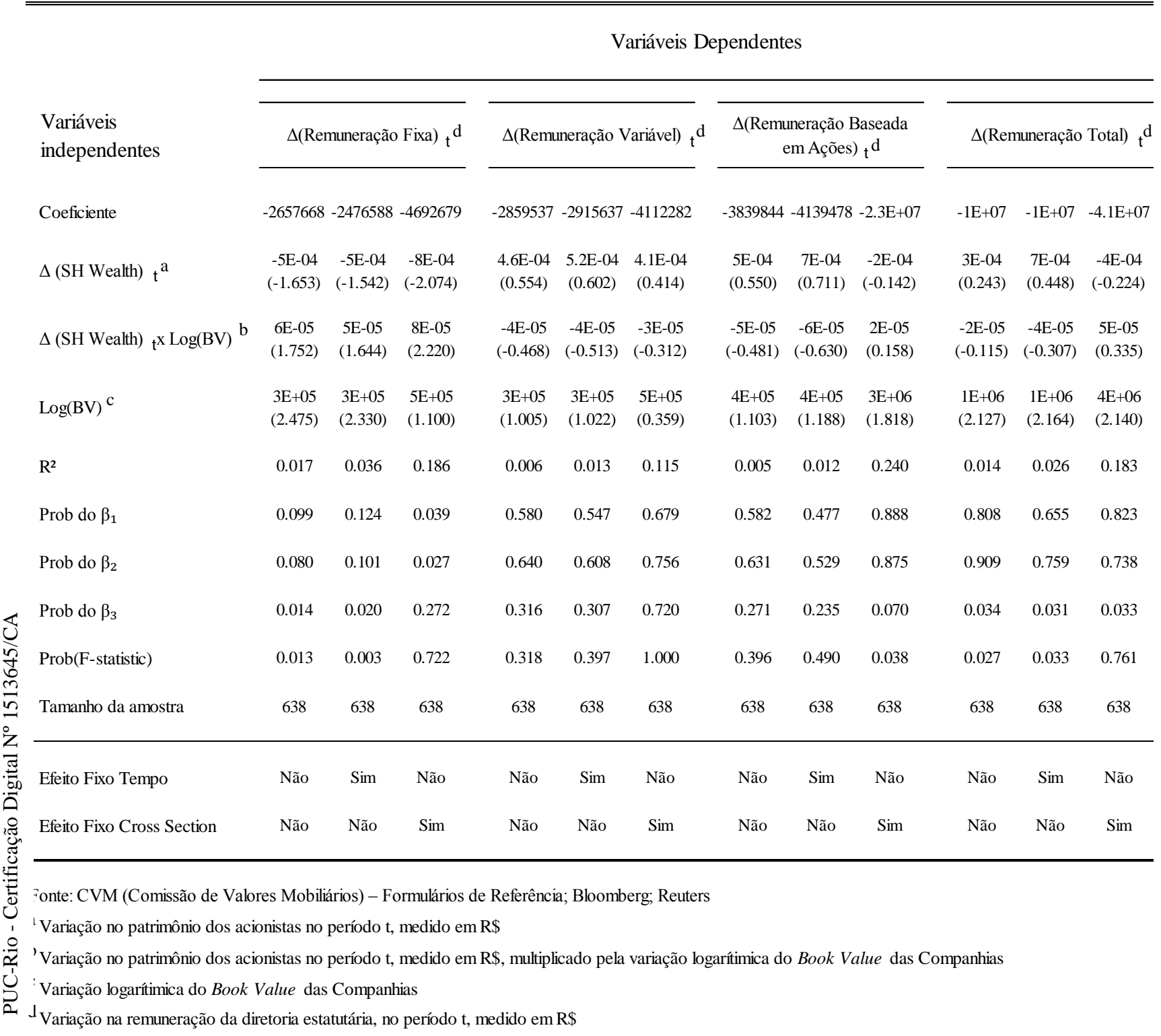


Tabela 7: Relação Entre a Remuneração Média dos Executivos e a Variação no Patrimônio dos Acionistas, Ponderando pela Volatilidade das Companhias

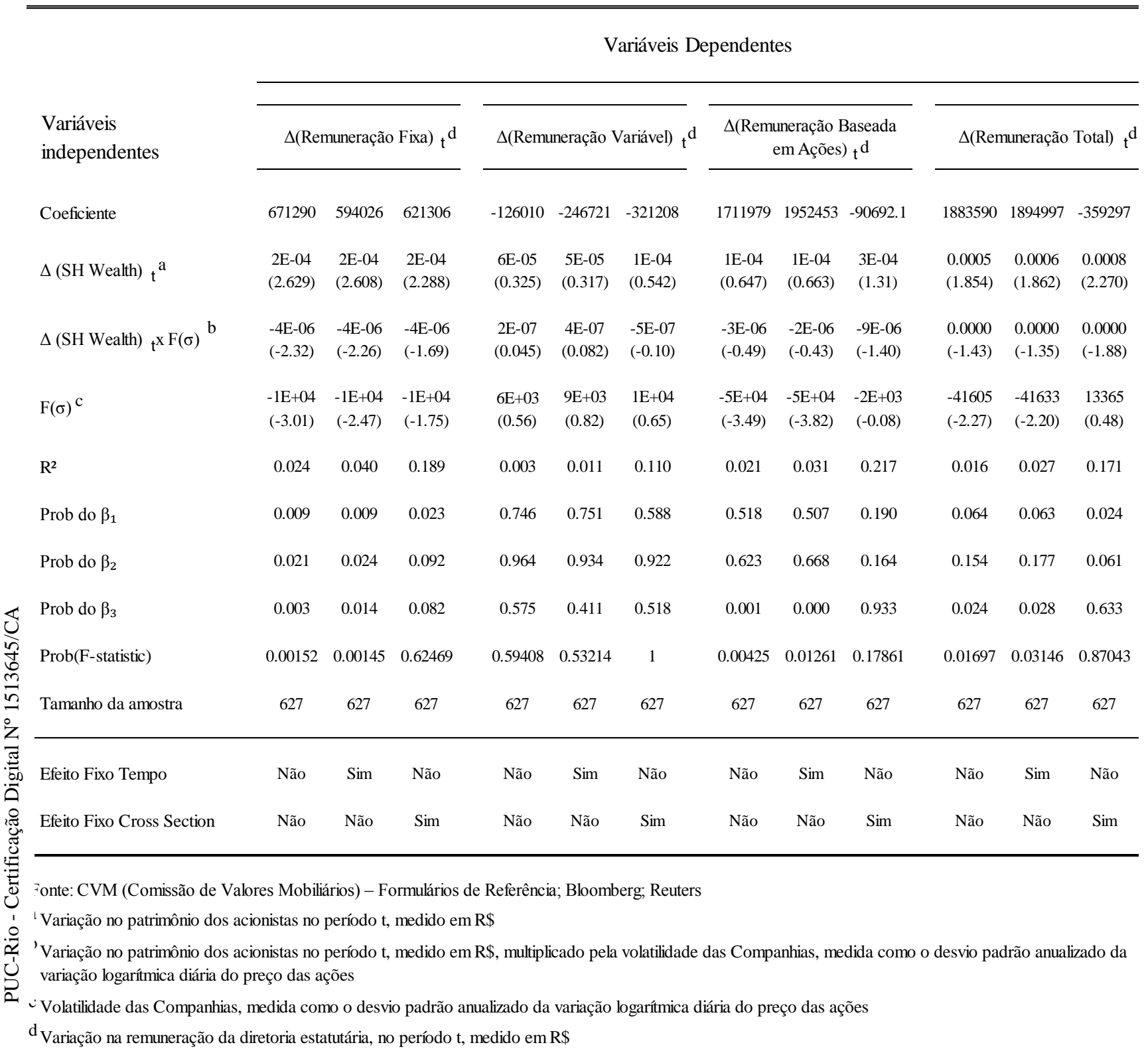


Tabela 9: Relação Entre a Remuneração dos Executivos e a Variação na Receita Líquida das Companhias

\begin{tabular}{|c|c|c|c|c|c|c|c|c|c|c|c|c|}
\hline \multirow{3}{*}{$\begin{array}{l}\text { Variáveis } \\
\text { independentes } \\
\text { Coeficiente }\end{array}$} & \multicolumn{12}{|c|}{ Variáveis Dependentes } \\
\hline & \multicolumn{3}{|c|}{$\Delta$ (Remuneração Fixa) $\mathrm{t}^{\mathrm{b}}$} & \multicolumn{3}{|c|}{$\Delta$ (Remuneração Variável) $\mathrm{t}^{\mathrm{b}}$} & \multicolumn{3}{|c|}{$\begin{array}{c}\Delta \text { (Remuneração Baseada } \\
\text { em Ações) } \mathrm{t}^{\mathrm{b}}\end{array}$} & \multicolumn{3}{|c|}{$\Delta$ (Remuneração Total) $\mathrm{t}^{\mathrm{b}}$} \\
\hline & 274395 & 274211 & 319732 & 214841 & 221931 & 168473 & 57639.5 & 64207 & 47804.4 & 625.83 & 638079 & 641163 \\
\hline$\Delta$ Receita Líquida $\mathrm{t}^{\mathrm{a}}$ & $\begin{array}{l}2.8 \mathrm{E}-06 \\
(0.115)\end{array}$ & $\begin{array}{l}3.2 \mathrm{E}-06 \\
(0.132)\end{array}$ & $\begin{array}{l}-1 \mathrm{E}-04 \\
(-2.498)\end{array}$ & $\begin{array}{l}1.1 \mathrm{E}-04 \\
(1.514)\end{array}$ & $\begin{array}{l}9.1 \mathrm{E}-05 \\
(1.290)\end{array}$ & $\begin{array}{l}2.1 \mathrm{E}-04 \\
(1.753)\end{array}$ & $\begin{array}{l}8.1 \mathrm{E}-05 \\
(0.932)\end{array}$ & $\begin{array}{l}6.6 \mathrm{E}-05 \\
(0.762)\end{array}$ & $\begin{array}{l}1 \mathrm{E}-04 \\
(0.717)\end{array}$ & $\begin{array}{l}1.4 \mathrm{E}-04 \\
(1.102)\end{array}$ & $\begin{array}{l}1.1 \mathrm{E}-04 \\
(0.885)\end{array}$ & $\begin{array}{l}1.0 \mathrm{E}-04 \\
(0.497)\end{array}$ \\
\hline $\mathrm{R}^{2}$ & 0.000 & 0.023 & 0.163 & 0.003 & 0.017 & 0.042 & 0.001 & 0.011 & 0.091 & 0.002 & 0.023 & 0.067 \\
\hline Prob do $\beta$ & 0.909 & 0.895 & 0.013 & 0.130 & 0.198 & 0.080 & 0.352 & 0.446 & 0.473 & 0.271 & 0.376 & 0.619 \\
\hline Prob(F-statistic) & 0.908 & 0.013 & 0.830 & 0.130 & 0.064 & 1.000 & 0.352 & 0.244 & 1.000 & 0.271 & 0.012 & 1.000 \\
\hline Tamanho da amostra & 709 & 709 & 709 & 709 & 709 & 709 & 709 & 709 & 709 & 709 & 709 & 709 \\
\hline Efeito Fixo Tempo & Não & Sim & Não & Não & Sim & Não & Não & Sim & Não & Não & Sim & Não \\
\hline Efeito Fixo Cross Section & Não & Não & Sim & Não & Não & Sim & Não & Não & Sim & Não & Não & Sim \\
\hline
\end{tabular}

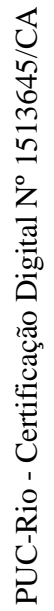

onte: CVM (Comissão de Valores Mobiliários) - Formulários de Referência; Bloomberg; Reuters

'Variação da Receita Líquida da Companhia, no período t, medido em R\$

, Variação na remuneração da diretoria estatutária, no período t, medido em R\$ 
Tabela 10: Relação Entre a Remuneração Média dos Executivos e a Variação na Receita Líquida das Companhias

\begin{tabular}{|c|c|c|c|c|c|c|c|c|c|c|c|c|}
\hline \multirow{3}{*}{$\begin{array}{l}\text { Variáveis } \\
\text { independentes } \\
\text { Coeficiente }\end{array}$} & \multicolumn{12}{|c|}{ Variáveis Dependentes } \\
\hline & \multicolumn{3}{|c|}{$\begin{array}{c}\Delta \text { (Remuneração Fixa } \\
\text { Média }) t^{b}\end{array}$} & \multicolumn{3}{|c|}{$\begin{array}{c}\Delta \text { (Remuneração Variável } \\
\text { Média }{ }_{\mathrm{t}} \mathrm{b}\end{array}$} & \multicolumn{3}{|c|}{$\begin{array}{l}\Delta \text { (Remuneração Média } \\
\text { Baseada em Ações) } \mathrm{t}^{\mathrm{b}}\end{array}$} & \multicolumn{3}{|c|}{$\begin{array}{c}\Delta \text { (Remuneração Total } \\
\text { Média })_{t} b\end{array}$} \\
\hline & 47956.3 & 47740.9 & 49163.1 & 35058 & 36178.2 & 28504 & -6821.91 & -5966.74 & -8206.07 & 87783 & 89134.9 & 84142.4 \\
\hline$\Delta$ Receita Líquida $\mathrm{t}^{\mathrm{a}}$ & $\begin{array}{l}1.5 \mathrm{E}-06 \\
(0.305)\end{array}$ & $\begin{array}{l}1.9 \mathrm{E}-06 \\
(0.403)\end{array}$ & $\begin{array}{l}-1 \mathrm{E}-06 \\
(-0.157)\end{array}$ & $\begin{array}{l}1.1 \mathrm{E}-05 \\
(0.617)\end{array}$ & $\begin{array}{l}8.7 \mathrm{E}-06 \\
(0.479)\end{array}$ & $\begin{array}{l}2.5 \mathrm{E}-05 \\
(0.834)\end{array}$ & $\begin{array}{l}1.1 \mathrm{E}-05 \\
(0.632)\end{array}$ & $\begin{array}{c}9.6 \mathrm{E}-06 \\
(0.526)\end{array}$ & $\begin{array}{c}1 \mathrm{E}-05 \\
(0.484)\end{array}$ & $\begin{array}{l}1.8 \mathrm{E}-05 \\
(0.664)\end{array}$ & $\begin{array}{l}1.5 \mathrm{E}-05 \\
(0.556)\end{array}$ & $\begin{array}{c}2.6 \mathrm{E}-05 \\
(0.568)\end{array}$ \\
\hline $\mathrm{R}^{2}$ & 0.000 & 0.687 & 0.173 & 0.001 & 0.011 & 0.034 & 0.001 & 0.009 & 0.082 & 0.001 & 0.018 & 0.055 \\
\hline Prob do $\beta$ & 0.760 & 0.687 & 0.875 & 0.537 & 0.632 & 0.405 & 0.528 & 0.599 & 0.629 & 0.507 & 0.578 & 0.570 \\
\hline $\operatorname{Prob}(F-$-statistic $)$ & 0.760 & 0.115 & 0.669 & 0.537 & 0.266 & 1.000 & 0.528 & 0.356 & 1.000 & 0.507 & 0.049 & 1.000 \\
\hline Tamanho da amostra & 709 & 709 & 709 & 709 & 709 & 709 & 709 & 709 & 709 & 709 & 709 & 709 \\
\hline Efeito Fixo Tempo & Não & Sim & Não & Não & Sim & Não & Não & $\operatorname{Sim}$ & Não & Não & $\operatorname{Sim}$ & Não \\
\hline Efeito Fixo Cross Section & Não & Não & Sim & Não & Não & Sim & Não & Não & $\operatorname{Sim}$ & Não & Não & $\operatorname{Sim}$ \\
\hline
\end{tabular}

onte: CVM (Comissão de Valores Mobiliários) - Formulários de Referência; Bloomberg; Reuters

'Variação da Receita Líquida da Companhia, no período t, medido em R\$

, Variação na remuneração média por diretor da diretoria estatutária, no período t, medido em $\mathrm{R} \$$ 
Tabela 11: Relação Entre a Remuneração dos Executivos e a Variação no EBITDA das Companhias

\begin{tabular}{|c|c|c|c|c|c|c|c|c|c|c|c|c|}
\hline \multirow{3}{*}{$\begin{array}{l}\text { Variáveis } \\
\text { independentes } \\
\text { Coeficiente }\end{array}$} & \multicolumn{12}{|c|}{ Variáveis Dependentes } \\
\hline & \multicolumn{3}{|c|}{$\Delta$ (Remuneração Fixa) $\mathrm{t}^{\mathrm{b}}$} & \multicolumn{3}{|c|}{$\Delta$ (Remuneração Variável) $\mathrm{t}^{\mathrm{b}}$} & \multicolumn{3}{|c|}{$\begin{array}{c}\Delta \text { (Remuneração Baseada } \\
\text { em Ações) } t^{b}\end{array}$} & \multicolumn{3}{|c|}{$\Delta$ (Remuneração Total) $\mathrm{t}^{\mathrm{b}}$} \\
\hline & 268456 & 267512 & 272330 & 254364 & 253486 & 254482 & 66520.9 & 66322.5 & 61748.3 & 661280 & 659711 & 664045 \\
\hline$\Delta$ EBITDA $_{\mathrm{t}}{ }^{\mathrm{a}}$ & $\begin{array}{l}7.7 \mathrm{E}-05 \\
(1.875)\end{array}$ & $\begin{array}{l}8.7 \mathrm{E}-05 \\
(2.130)\end{array}$ & $\begin{array}{l}4 \mathrm{E}-05 \\
(0.763)\end{array}$ & $\begin{array}{l}9.6 \mathrm{E}-05 \\
(0.807)\end{array}$ & $\begin{array}{l}1.1 \mathrm{E}-04 \\
(0.887)\end{array}$ & $\begin{array}{l}9.4 \mathrm{E}-05 \\
(0.656)\end{array}$ & $\begin{array}{l}3.0 \mathrm{E}-04 \\
(2.050)\end{array}$ & $\begin{array}{l}3.0 \mathrm{E}-04 \\
(2.059)\end{array}$ & $\begin{array}{c}3 \mathrm{E}-04 \\
(2.034)\end{array}$ & $\begin{array}{l}2.8 \mathrm{E}-04 \\
(1.359)\end{array}$ & $\begin{array}{l}3.0 \mathrm{E}-04 \\
(1.446)\end{array}$ & $\begin{array}{l}2.5 \mathrm{E}-04 \\
(1.017)\end{array}$ \\
\hline $\mathrm{R}^{2}$ & 0.005 & 0.029 & 0.154 & 0.001 & 0.016 & 0.038 & 0.006 & 0.016 & 0.096 & 0.003 & 0.025 & 0.068 \\
\hline Prob do $\beta$ & 0.061 & 0.034 & 0.446 & 0.420 & 0.376 & 0.512 & 0.041 & 0.040 & 0.042 & 0.175 & 0.149 & 0.310 \\
\hline Prob(F-statistic) & 0.061 & 0.002 & 0.917 & 0.420 & 0.087 & 1.000 & 0.041 & 0.072 & 1.000 & 0.174 & 0.007 & 1.000 \\
\hline Tamanho da amostra & 709 & 709 & 709 & 709 & 709 & 709 & 709 & 709 & 709 & 709 & 709 & 709 \\
\hline Efeito Fixo Tempo & Não & $\operatorname{Sim}$ & Não & Não & Sim & Não & Não & $\operatorname{Sim}$ & Não & Não & Sim & Não \\
\hline Efeito Fixo Cross Section & Não & Não & Sim & Não & Não & Sim & Não & Não & Sim & Não & Não & Sim \\
\hline
\end{tabular}

onte: CVM (Comissão de Valores Mobiliários) - Formulários de Referência; Bloomberg; Reuters

'Variação do EBITDA da Companhia no período t, medido em R\$

'Variação na remuneração da diretoria estatutária, no período t, medido em R\$ 
Tabela 12: Relação Entre a Remuneração Média dos Executivos e a Variação no EBITDA das Companhias

\begin{tabular}{|c|c|c|c|c|c|c|c|c|c|c|c|c|}
\hline \multirow{3}{*}{$\begin{array}{l}\text { Variáveis } \\
\text { independentes } \\
\text { Coeficiente }\end{array}$} & \multicolumn{12}{|c|}{ Variáveis Dependentes } \\
\hline & \multicolumn{3}{|c|}{$\begin{array}{c}\Delta \text { (Remuneração Fixa } \\
\text { Média) } \mathrm{t}_{\mathrm{b}}^{\mathrm{b}}\end{array}$} & \multicolumn{3}{|c|}{$\begin{array}{c}\Delta \text { (Remuneração Variável } \\
\text { Média) } \mathrm{t}^{\mathrm{b}}\end{array}$} & \multicolumn{3}{|c|}{$\begin{array}{l}\Delta \text { (Remuneração Média } \\
\text { Baseada em Ações) } \mathrm{t}^{\mathrm{b}}\end{array}$} & \multicolumn{3}{|c|}{$\begin{array}{c}\Delta \text { (Remuneração Total } \\
\text { Média }) \mathrm{t}^{\mathrm{b}}\end{array}$} \\
\hline & 48849.3 & 48701 & 49047.4 & 37866.5 & 37522.6 & 37347.9 & -8373.7 & -8356.87 & -10009.9 & 89453.5 & 89107.6 & 88125.4 \\
\hline$\Delta$ EBITDA $_{t}{ }^{a}$ & $\begin{array}{c}-2 \mathrm{E}-06 \\
(-0.298)\end{array}$ & $\begin{array}{c}-8 \mathrm{E}-07 \\
(-0.102)\end{array}$ & $\begin{array}{c}-5 \mathrm{E}-06 \\
(-0.498)\end{array}$ & $\begin{array}{l}2.4 \mathrm{E}-05 \\
(0.797)\end{array}$ & $\begin{array}{l}2.8 \mathrm{E}-05 \\
(0.916)\end{array}$ & $\begin{array}{l}3.0 \mathrm{E}-05 \\
(0.805)\end{array}$ & $\begin{array}{l}7.2 \mathrm{E}-05 \\
(2.380)\end{array}$ & $\begin{array}{c}7.2 \mathrm{E}-05 \\
(2.367)\end{array}$ & $\begin{array}{c}9 \mathrm{E}-05 \\
(2.495)\end{array}$ & $\begin{array}{l}7.2 \mathrm{E}-05 \\
(1.539)\end{array}$ & $\begin{array}{c}7.5 \mathrm{E}-05 \\
(1.621)\end{array}$ & $\begin{array}{c}8.6 \mathrm{E}-05 \\
(1.534)\end{array}$ \\
\hline $\mathrm{R}^{2}$ & 0.000 & 0.014 & 0.173 & 0.001 & 0.012 & 0.034 & 0.008 & 0.017 & 0.091 & 0.003 & 0.021 & 0.058 \\
\hline Prob do $\beta$ & 0.766 & 0.919 & 0.619 & 0.426 & 0.360 & 0.421 & 0.018 & 0.018 & 0.013 & 0.124 & 0.105 & 0.126 \\
\hline Prob(F-statistic) & 0.766 & 0.121 & 0.663 & 0.426 & 0.221 & 1.000 & 0.018 & 0.063 & 1.000 & 0.124 & 0.021 & 1.000 \\
\hline Tamanho da amostra & 709 & 709 & 709 & 709 & 709 & 709 & 709 & 709 & 709 & 709 & 709 & 709 \\
\hline Efeito Fixo Tempo & Não & $\operatorname{Sim}$ & Não & Não & Sim & Não & Não & $\operatorname{Sim}$ & Não & Não & Sim & Não \\
\hline Efeito Fixo Cross Section & Não & Não & Sim & Não & Não & Sim & Não & Não & Sim & Não & Não & Sim \\
\hline
\end{tabular}


Tabela 13: Relação Entre a Remuneração dos Executivos e a Variação no Lucro Líquido das Companhias

\begin{tabular}{|c|c|c|c|c|c|c|c|c|c|c|c|c|}
\hline \multirow{3}{*}{$\begin{array}{l}\text { Variáveis } \\
\text { independentes } \\
\text { Coeficiente }\end{array}$} & \multicolumn{12}{|c|}{ Variáveis Dependentes } \\
\hline & \multicolumn{3}{|c|}{$\Delta$ (Remuneração Fixa) $\mathrm{t}^{\mathrm{b}}$} & \multicolumn{3}{|c|}{$\Delta$ (Remuneração Variável) $\mathrm{t}^{\mathrm{b}}$} & \multicolumn{3}{|c|}{$\begin{array}{c}\Delta \text { (Remuneração Baseada } \\
\text { em Ações) } t^{b}\end{array}$} & \multicolumn{3}{|c|}{$\Delta$ (Remuneração Total) $\mathrm{t}^{\mathrm{t}}$} \\
\hline & 275706 & 275776 & 275695 & 263780 & 263863 & 263732 & 98060.6 & 98135.6 & 98081.9 & 690634 & 690848 & 690540 \\
\hline$\Delta$ Lucro Líquido $t^{\mathrm{a}}$ & $\begin{array}{l}4.1 \mathrm{E}-06 \\
(0.103)\end{array}$ & $\begin{array}{l}1.5 \mathrm{E}-05 \\
(0.382)\end{array}$ & $\begin{array}{l}2 \mathrm{E}-06 \\
(0.059)\end{array}$ & $\begin{array}{l}7.5 \mathrm{E}-05 \\
(0.648)\end{array}$ & $\begin{array}{l}8.8 \mathrm{E}-05 \\
(0.760)\end{array}$ & $\begin{array}{l}6.7 \mathrm{E}-05 \\
(0.535)\end{array}$ & $\begin{array}{l}5.8 \mathrm{E}-04 \\
(4.086)\end{array}$ & $\begin{array}{l}5.9 \mathrm{E}-04 \\
(4.155)\end{array}$ & $\begin{array}{l}6 \mathrm{E}-04 \\
(3.891)\end{array}$ & $\begin{array}{l}4.8 \mathrm{E}-04 \\
(2.401)\end{array}$ & $\begin{array}{l}5.2 \mathrm{E}-04 \\
(2.576)\end{array}$ & $\begin{array}{l}4.7 \mathrm{E}-04 \\
(2.172)\end{array}$ \\
\hline $\mathrm{R}^{2}$ & 0.000 & 0.023 & 0.154 & 0.001 & 0.015 & 0.038 & 0.023 & 0.034 & 0.113 & 0.008 & 0.031 & 0.074 \\
\hline Prob do $\beta$ & 0.918 & 0.703 & 0.953 & 0.517 & 0.447 & 0.593 & 0.000 & 0.000 & 0.000 & 0.017 & 0.010 & 0.030 \\
\hline $\operatorname{Prob}(\mathrm{F}$-statistic) & 0.918 & 0.012 & 0.923 & 0.517 & 0.094 & 1.000 & 0.000 & 0.000 & 1.000 & 0.017 & 0.001 & 1.000 \\
\hline Tamanho da amostra & 709 & 709 & 709 & 709 & 709 & 709 & 709 & 709 & 709 & 709 & 709 & 709 \\
\hline Efeito Fixo Tempo & Não & Sim & Não & Não & Sim & Não & Não & Sim & Não & Não & Sim & Não \\
\hline Efeito Fixo Cross Section & Não & Não & $\operatorname{Sim}$ & Não & Não & Sim & Não & Não & Sim & Não & Não & Sim \\
\hline
\end{tabular}

onte: CVM (Comissão de Valores Mobiliários) - Formulários de Referência; Bloomberg; Reuters

'Variação do Lucro Líquido da Companhia no período t, medido em R\$

'Variação na remuneração da diretoria estatutária, no período t, medido em R\$ 
Tabela 14: Relação Entre a Remuneração Média dos Executivos e a Variação no Lucro Líquido das Companhias

\begin{tabular}{|c|c|c|c|c|c|c|c|c|c|c|c|c|}
\hline \multirow{3}{*}{$\begin{array}{l}\text { Variáveis } \\
\text { independentes } \\
\text { Coeficiente }\end{array}$} & \multicolumn{12}{|c|}{ Variáveis Dependentes } \\
\hline & \multicolumn{3}{|c|}{$\begin{array}{c}\Delta \text { (Remuneração Fixa } \\
\text { Média }) t^{b}\end{array}$} & \multicolumn{3}{|c|}{$\begin{array}{c}\Delta \text { (Remuneração Variável } \\
\text { Média) } \mathrm{t}^{\mathrm{b}}\end{array}$} & \multicolumn{3}{|c|}{$\begin{array}{l}\Delta \text { (Remuneração Média } \\
\text { Baseada em Ações) } \mathrm{t}^{\mathrm{b}}\end{array}$} & \multicolumn{3}{|c|}{$\begin{array}{c}\Delta \text { (Remuneração Total } \\
\text { Média }) \mathrm{t}^{\mathrm{b}}\end{array}$} \\
\hline & 48585 & 48598.3 & 48585 & 40247.5 & 40282.5 & 40235.9 & -845.846 & -830.275 & -843.002 & 96724.3 & 96783.5 & 96705.2 \\
\hline$\Delta$ Lucro Líquido $t^{\mathrm{a}}$ & $\begin{array}{c}-6 \mathrm{E}-06 \\
(-0.787)\end{array}$ & $\begin{array}{c}-4 \mathrm{E}-06 \\
(-0.518)\end{array}$ & $\begin{array}{r}-6 \mathrm{E}-06 \\
(-0.781)\end{array}$ & $\begin{array}{l}1.9 \mathrm{E}-05 \\
(0.624)\end{array}$ & $\begin{array}{c}2.4 \mathrm{E}-05 \\
(0.809)\end{array}$ & $\begin{array}{l}1.7 \mathrm{E}-05 \\
(0.515)\end{array}$ & $\begin{array}{l}1.2 \mathrm{E}-04 \\
(4.053)\end{array}$ & $\begin{array}{l}1.2 \mathrm{E}-04 \\
(4.119)\end{array}$ & $\begin{array}{c}1 \mathrm{E}-04 \\
(3.834)\end{array}$ & $\begin{array}{l}9.2 \mathrm{E}-05 \\
(2.024)\end{array}$ & $\begin{array}{l}1.0 \mathrm{E}-04 \\
(2.231)\end{array}$ & $\begin{array}{c}8.9 \mathrm{E}-05 \\
(1.815)\end{array}$ \\
\hline $\mathrm{R}^{2}$ & 0.001 & 0.015 & 0.174 & 0.001 & 0.011 & 0.033 & 0.023 & 0.032 & 0.104 & 0.006 & 0.024 & 0.060 \\
\hline Prob do $\beta$ & 0.432 & 0.605 & 0.435 & 0.533 & 0.419 & 0.607 & 0.000 & 0.000 & 0.000 & 0.043 & 0.026 & 0.070 \\
\hline Prob(F-statistic) & 0.432 & 0.111 & 0.654 & 0.533 & 0.234 & 1.000 & 0.000 & 0.001 & 1.000 & 0.043 & 0.008 & 1.000 \\
\hline Tamanho da amostra & 709 & 709 & 709 & 709 & 709 & 709 & 709 & 709 & 709 & 709 & 709 & 709 \\
\hline Efeito Fixo Tempo & Não & Sim & Não & Não & Sim & Não & Não & $\operatorname{Sim}$ & Não & Não & Sim & Não \\
\hline Efeito Fixo Cross Section & Não & Não & Sim & Não & Não & Sim & Não & Não & Sim & Não & Não & Sim \\
\hline
\end{tabular}

onte: CVM (Comissão de Valores Mobiliários) - Formulários de Referência; Bloomberg; Reuters

'Variação do Lucro Líquido da Companhia no período t, medido em R\$

'Variação na remuneração média por diretor da diretoria estatutária, no período t, medido em $\mathrm{R} \$$ 